\title{
Accounting for surface waves improves gas flux estimation at high wind speed in a large lake
}

Pascal Perolo ${ }^{1}$, Bieito Fernandez Castro ${ }^{2,3}$, Nicolas Escoffier ${ }^{1}$, Thibault Lambert ${ }^{1}$, Damien Bouffard ${ }^{4}$, Marie-Elodie Perga ${ }^{1}$

$5 \quad{ }^{1}$ Institute of Earth Surface Dynamics, University of Lausanne, Lausanne, 1015, Switzerland

${ }^{2}$ Physics of Aquatic Systems Laboratory, Margareth Kamprad Chair, Swiss Federal Institute of Technology Lausanne, Lausanne, 1015, Switzerland

${ }^{3}$ Ocean and Earth Science, University of Southampton, National Oceanography Centre, Southampton, SO14 3ZH, United Kingdom

$10{ }^{4}$ Eawag, Swiss Federal Institute of Aquatic Science and Technology, Surface Waters - Research Management, Kastanienbaum, 6047, Switzerland

Correspondence to: Pascal Perolo (pascal.perolo@unil.ch)

\begin{abstract}
The gas transfer velocity $(k)$ is a major source of uncertainty when assessing the magnitude of lake gas exchange with the atmosphere. For the diversity of existing empirical and process-based $k$ models, the transfer velocity increases with

15 the level of turbulence near the air-water interface. However, predictions for $k$ can vary by a factor of 2 among different models. Near-surface turbulence results from the action of wind shear, surface waves and buoyancy-driven convection. Wind shear has long been identified as a key driver, while recent lake studies have shifted the focus towards the role of convection, particularly in small lakes. In large lakes, wind fetch can however be long enough to generate surface waves and contribute to enhance gas transfer, as widely recognised in oceanographic studies. Here, field values for gas transfer velocity were computed in a large

20 hardwater lake, Lake Geneva, from $\mathrm{CO}_{2}$ fluxes measured with an automated (forced diffusion) flux chamber and $\mathrm{CO}_{2}$ partial pressure measured with high frequency sensors. $k$ estimates were compared to a set of reference limnological and oceanic $k$ models. Our analysis reveals that accounting for surface waves generated during windy events significantly improves the accuracy of $k$ estimates in this large lake. The improved $k$ model is then used to compute $k$ over a one-year time-period. Results show that episodic extreme events with surface waves ( $6 \%$ occurrence, significant wave height $>0.4 \mathrm{~m}$ ) can generate more

25 than $20 \%$ of annual cumulative $k$ and more than $25 \%$ of annual net $\mathrm{CO}_{2}$ fluxes in Lake Geneva. We conclude that for lakes whose fetch can exceed $15 \mathrm{~km}, k$-models need to integrate the effect of surface waves.
\end{abstract}

\section{Introduction}

Lakes are universally regarded as significant sources of $\mathrm{CO}_{2}$ to the atmosphere, however, the accurate quantification of the magnitude of such emissions remains to date challenging (Cole et al., 2007; Tranvik et al., 2009; Raymond et al., 2013). While $30 \mathrm{CO}_{2}$ fluxes can be directly measured with floating chamber or eddy covariance systems (Vachon et al., 2010; Vesala et al., 2006), these approaches suffer from limited time and space integration (from minutes to hours, and centimetres to metres; 
Klaus and Vachon, 2020). Long-term direct flux measurements are thereby mostly restricted to small lakes (Huotari et al., 2011) and fluxes remain mostly estimated with models. $\mathrm{CO}_{2}$ fluxes at the surface of lakes operate through a net diffusive transport, therefore obeying the Fick's first law:

$35 \mathrm{~F}=\mathrm{k \alpha} \alpha \mathrm{pCO} \mathrm{O}_{2}$,

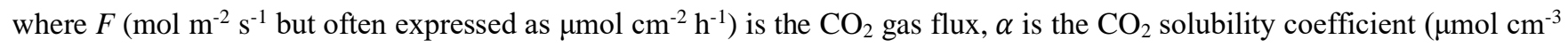
$\left.\mu \mathrm{atm}^{-1}\right), \Delta p C \mathrm{O}_{2}$ is the gradient of partial pressure of $\mathrm{CO}_{2}\left(\mathrm{pCO}_{2}\right)$ between the water and the atmosphere corrected for altitude ( $\mu \mathrm{atm})$; and $k$ is the gas transfer velocity $\left(\mathrm{cm} \mathrm{h}^{-1}\right)$.

40 Lake carbon emissions are therefore primarily driven by the gradient of partial pressure of $\mathrm{CO}_{2}$ between the surface lake water and the atmosphere, but the gas-transfer velocity controls the rate of $\mathrm{CO}_{2}$ exchange across the lake-atmosphere interface. Assessing the amount of lake $\mathrm{CO}_{2}$ emissions to the atmosphere has been a major issue, starting with the Cole and al's 1998 seminal paper, with debates regarding both the representativeness of the measurements and the optimal conceptual model for air-water gas transfer (e.g., MacIntyre et al., 2001; Borges et al., 2004). As recent developments in sensor technologies allow continuous and accurate measurements of aqueous $\mathrm{CO}_{2}$ concentrations, the gas transfer velocity remains, to date, the main source of uncertainties, which hinders attempts to achieve full carbon budgets (Dugan et al., 2016) or to quantify greenhouse gas emissions by lakes, at local, regional, or worldwide scales (Maberly et al., 2012; Raymond et al., 2013; Engel et al., 2018).

$k$ is inherently tied to turbulent mixing within the surface boundary layer, which enhances the diffusive gas exchange by renewing the surface mass content (Zappa et al., 2007). At the lake-atmosphere interface, turbulent mixing is the product of wind shear, buoyancy flux, and wind-driven surface waves, whose effect can be split into wave action and wave breaking, the latter producing air bubble and water spray (Fig. 1; Wüest and Lorke, 2003, Soloviev et al., 2007). Regarding the prominent role of wind action on surface turbulence, first quantitative models have empirically scaled $k$ to wind-speed (referenced at a $10 \mathrm{~m}$ height; $U_{10}$ ), as a proxy for the level of wind-driven turbulence (Fig. 1; Cole and Caraco, 1998; Crusius and Wanninkhof,

55 2003). The parameterizations of the $k$-wind relationships vary between authors (e.g., Klaus and Vachon 2020), as a likely consequence of the local characteristics of the lakes used in the calibration datasets (Table 1). Yet, all studies suggested a polynomial relationship between $U_{10}$ and $k$ with order larger than unity. Further development of empirical models integrated the lake surface area as a second parameter in the $k$-wind relationships, to account for the role of the fetch length for wind action (Vachon and Prairie, 2013). Generally, empirical wind-based models tend to underestimate fluxes, especially at low-

60 wind speed (e.g., Schubert et al., 2012; Heiskanen et al., 2014; Mammarella et al., 2015) where turbulent mixing through buoyancy flux is expected to take over wind shear. Besides, these empirical models require a proper calibration each time they are applied in a new system with different characteristics, i.e., a new set of lakes and/or meteorological conditions (Klaus and Vachon, 2020), hence limiting their universal applicability.

\section{Figure 1}


65 In parallel to empirical wind-based models, process-based models attempt to link $k$ directly to near-surface turbulence. The surface renewal model (SRM) is one of the first, and still most widely used, theories (Danckwerts 1951; Lamont and Scott, 1970) with $k$ depending on the product of the turbulent kinetic energy dissipation rate $(\varepsilon)$ and the kinematic viscosity of water $(v)$, both to a power of one quarter as follows:

$k=a_{1}(\varepsilon v)^{1 / 4} S c^{-1 / 2}$,

70 with $a_{1}$ a calibration constant parameter and $S c$, the Schmidt number. Recently Lorke and Peeters (2006) and Katul and Liu (2017) demonstrated that this relationship, to which different approaches converge, can be seen as a universal scaling. As opposed to the practical empirical models presented above, process-based models have the potential to predict $k$ using the turbulent dissipation rate over a wide range of environmental conditions extending beyond those encountered in the calibration dataset (Zappa et al., 2007). As for lakes, SRM $k$-models have so far considered the friction velocity at the water side $\left(u_{\text {,wat }}\right)$

75 and the turbulence created by thermal convection using the buoyancy flux at the surface $\left(B_{0}\right)$ (Fig. 1; Eugster et al., 2003; MacIntyre et al., 2010; Read et al., 2012; Tedford et al., 2014; Heiskanen et al., 2014). Noteworthily, the SRM approach leads to $k$ being related to $u_{\text {,wat }}$ (or $U_{10}$ ) to the first order (Wanninkhof, 1992; Lorke and Peeters 2006; see also Material and Methods section), while empirical models described above predict a higher order polynomial relationship. This inconsistency is tentatively solved in oceanography by adding another source of gas exchange associated with wind-waves whitecaps. Early 80 gas flux parameterization already accounted for wind and buoyancy-driven turbulence together with surface waves (Fig. 1; Woolf et al., 1997; Soloviev et al., 2007; Fairall et al., 2011). Yet, the buoyancy-driven contribution can often be neglected in oceanography, and recent efforts have been dedicated to a better parameterization of the bubble enhancement term (Fig. 1; Deike and Melville, 2018). In lakes, wind fetch can be long enough to generate surface waves (Wanninkhof, 1992; Frost and Upstill-Goddard, 2002; Borges et al., 2004; Guérin et al., 2007), thus implying that surface waves could be a significant driver 85 of $k$ and subsequent $\mathrm{CO}_{2}$ fluxes (Schilder et al., 2013; Vachon and Prairie, 2013). Insofar, the role of surface waves has been essentially accounted empirically in lake $k$-models, through the polynomial scaling to $U_{10}$ in wind-based models, and most often neglected in studies using process-based parameterizations (mainly SRM) (e.g., Read et al., 2012). While this approximation may be appropriate for small-shielded lakes, it is likely to be insufficient in larger, long-fetched lakes.

90 Herein, we aim to identify the most adequate $k$-model for Lake Geneva, a large clear hardwater lake in the Swiss Alps, to assess $k$ values over a full annual cycle. We compare the performances of different models of gas transfer velocity, in their original or slightly modified published formulations from the limnological and oceanic literatures. This set of models includes different levels of complexity, ranging from empirical models integrating wind speed and lake size, to process-based models including wind shear, convection, and surface waves. Continuous $\triangle p \mathrm{CO}_{2}$ measurements by in situ automated sensors and $\mathrm{CO}_{2}$

95 fluxes, obtained from a new generation of automated (forced diffusion) flux chamber, were collected during specific periods of intensive field survey covering a wide range of natural conditions. Empirical $k$ values computed from chamber data are then compared to outputs from the different $k$-models. Owing to the size of Lake Geneva, we anticipate that models accounting, 
implicitly or explicitly, for the four key exchange drivers (i.e., wind shear, convective mixing, wave action and bubble formation) will show the highest accuracy and precision in their estimation of $k$ and that a precise integration of surface wave effects in such a large system should enhance model predictions. Thereafter, the relative distribution of these components is computed over a full year and analysed in the scope of the temporal variability of the gas transfer velocity. Finally, we expect that extreme wind and associated wave events should contribute disproportionately to accumulated $k$ values over the year. In such a case, episodic weather events could generate large $\mathrm{CO}_{2}$ fluxes over very short timescales that should be accounted for when computing annual $\mathrm{CO}_{2}$ emission budgets.

\section{Material and Methods}

\subsection{Study Site}

Lake Geneva is a peri-alpine lake defining part of the Swiss-French border, at $372 \mathrm{~m}$ above sea level (46 $26^{\prime} \mathrm{N}$; 6 $33^{\prime}$ E). Its surface area $\left(582 \mathrm{~km}^{2}\right)$ and its maximum depth $(309 \mathrm{~m})$ make it the largest freshwater body in Western Europe, with a volume of $89 \mathrm{~km}^{3}$ (Fig. 2). Lake Geneva is monomictic. The two prevailing winds are nearly opposed and come from southwest and northeast respectively (Fig. 2). The lake water has been monthly or fortnightly surveyed from the late 1950's (OLA-IS, AnaEEFrance, INRAE of Thonon-les-Bains, CIPEL, Rimet et al., 2020). Surface $\mathrm{CO}_{2}$ concentrations, as computed from the routine temperature, alkalinity, and $\mathrm{pH}$ measurements (Stumm and Morgan, 1981), show a typical seasonal cycle with high, supersaturated values during winter mixing and values below saturation in summer (Perga et al., 2016).

\section{Figure 2}

\section{2.2 Field data at LéXPLORE}

All field data were collected from the LéXPLORE platform, a $10 \mathrm{~m}$ by $10 \mathrm{~m}$ pontoon equipped with high-tech instrumentation and installed on Lake Geneva in 2019. LéXPLORE is moored at a $110 \mathrm{~m}$ depth, $570 \mathrm{~m}$ off the northern lake shore (Fig. 2).

On LéXPLORE, local weather conditions (air temperature, wind speed and direction, relative humidity, short wave radiation and atmospheric pressure) were continuously recorded (10 minutes intervals) by a Campbell Scientific Automatic Weather Station. Lake surface temperature was measured every minute at $50 \mathrm{~cm}$-depth using a Minilog II-T (Vemco, resolution $0.01^{\circ}$ C). Partial pressure of water surface $\mathrm{CO}_{2}\left(\mathrm{pCO}_{2}\right)$ was also measured at $50 \mathrm{~cm}$-depth during specific surveys (see flux measurement) using a miniCO ${ }_{2}$ sensor (Pro-Oceanus Systems Inc.) with an accuracy of \pm 30 ppm. Values of pCO in ppm were converted into $\mu \mathrm{atm}$ following the basic equation correcting for altitude (Russell and Denn, 1972). We therefore assume that the concentration and the temperature are homogeneous over the first 50 centimetres.

Fetch distance $(\mathrm{m})$ from LéXPLORE to the lake shores considering wind direction was computed using data from the Federal Office of Topography online portal (Swisstopo-geoportal: geo.admin.ch). The position of LéXPLORE is particularly relevant 
for this study as the fetch ranges from $\sim 0.5 \mathrm{~km}$ to $\sim 30 \mathrm{~km}$ for the two prevailing winds. Significant wave height, $H_{\mathrm{s}}$, (in $\mathrm{m}$ )

was computed after Hasselmann et al. (1973) according to:

$H_{s}=1.6 \cdot 10^{-3} \cdot U_{10} \cdot(\text { Fetch } / g)^{1 / 2}$,

where $g$ is the gravitational constant. This equation is equivalent to the formulation by Carter (1982) that is more widely used in the oceanic literature. Simon (1997) tested the model for significant wave heights in Lake Neuchâtel (a nearby but smaller lake than Lake Geneva) with a fetch distance of $9 \mathrm{~km}$. His results showed that, beyond a critical threshold of wind value ( 5 $\mathrm{m} \mathrm{s}^{-1}$ ) wave breaking occurs faster and with a higher probability in the case of not fully developed surface waves. Such waves are characterized by steeper slopes that favour their breaking (Wüest and Lorke, 2003).

The net $\mathrm{CO}_{2}$ flux at the lake-atmosphere interface, $F$, was directly measured with an automated (forced diffusion) floating $\mathrm{CO}_{2}$ flux chamber (eosFD, eosense: environmental gas monitoring; Risk et al., 2011) originally developed for soil flux studies. The

140 flux chamber had a detection limit close to $0.05 \mu \mathrm{mol} \mathrm{cm} \mathrm{cm}^{-2} \mathrm{~h}^{-1}$ and measured $F$ every 15 -minutes in summer and 30 -minutes in winter for battery-saving purpose. The standard floating chambers require quiet surface conditions (e.g., Cole et al., 2010; Vachon et al., 2010; Bastviken et al., 2015), thus limiting studies from low to moderate wind speed conditions. One typical problem with floating chambers arises from the possible atmospheric leakage under rough surface. Our flux chamber was specifically conceived to increase stability under windy conditions (Fig. A1). We tested the performance of the floating

145 chamber by comparing the standard deviation of the $\mathrm{CO}_{2}$ concentrations of the atmosphere and in the chamber estimated from two separated cavities (Fig. A1; Risk et al., 2011). We did not observe any difference in the standard deviation between high and low wind conditions (Fig A3), suggesting that the measured fluxes remained reliable at high wind speed.

We assessed the performances of our flux chamber during 5 specific periods over the annual cycle (i.e., $13^{\text {th }}-14^{\text {th }}$ June 2019 , $15027^{\text {th }}-28^{\text {th }}$ August $2019,1^{\text {st }}-5^{\text {th }}$ October $2019,18^{\text {th }}-20^{\text {th }}$ December 2019 , and $20^{\text {th }}-26^{\text {th }}$ February 2020$)$. To select the most robust dataset to compare with $k$ estimates derived from models, we discarded flux data that were below the detection limit, as well as $\mathrm{CO}_{2}$ gradients that ranged within the uncertainty of sensors (i.e., \pm 20 ppm for air and \pm 30 ppm for water leading to \pm 50 ppm) (Fig. A2). Accordingly, we were able to retain the most robust data points during the following deployment periods: $18^{\text {th }}-20^{\text {th }}$ December 2019 and $20^{\text {th }}-26^{\text {th }}$ February 2020. Finally, all these field data were standardized at a 1-hour timestep.

\subsection{Computed $k$ values from field data}

$k$ values $\left(\mathrm{cm} \mathrm{h}^{-1}\right)$ from field observations $\left(k_{\mathrm{obs}}\right)$ were computed from the gas transfer velocity equation:

$k_{o b s}=F /\left(\alpha \cdot \Delta p C O_{2}\right)$

where $F$ is the measured $\mathrm{CO}_{2}$ flux $\left(\mu \mathrm{mol} \mathrm{cm} \mathrm{cm}^{-2} \mathrm{~h}^{-1}\right), \alpha$ is the gas solubility coefficient $\left(\mu \mathrm{mol} \mathrm{cm}{ }^{-3} \mu \mathrm{atm}^{-1}\right)$, which depends on the measured water temperature (Wanninkhof, 1992). $\triangle p \mathrm{CO}_{2}$ is the differential of $\mathrm{pCO}_{2}$ measured at $0.5 \mathrm{~m}$ below the surface 
$160\left(\mathrm{pCO}_{2}{ }^{\text {water }}\right)$ and $\mathrm{pCO}_{2}$ at saturation $\left(\mathrm{pCO}_{2}{ }^{\text {sat }}\right)$ in $\mathrm{ppm}$ measured from the flux chamber corrected by altitude ( $\mu$ atm). $k_{\mathrm{obs}}$ was then standardized in $k_{600}$ using the dimensionless Schmidt number $(S c)$ of $\mathrm{CO}_{2}$ by the equation: $k_{600-o b s}=k_{o b s}$. $(600 / S c)^{-1 / 2}\left(600\right.$ for freshwater standardized at $\left.20^{\circ} \mathrm{C}\right)$.

\subsection{Models for air-water gas transfer velocity}

After years of debate, a consensus begins to emerge on the relationship linking $k$, intensity of turbulence and $S c$ (Eq. 2), even

165 when starting from different physical assumptions (see Katul et al., 2018). In this study, we selected six parameterizations widely used in limnology and oceanography combining specific calibration characteristics (Table 1). We first show that they can all be expressed following Eq. (2) for wind shear and convection, despite their different formulations. Then, we develop the effects of surface waves from oceanic models and adapt the wave action for a large lake. The final lake model integrating wave effect is ultimately calibrated using our field data (Table 1).

\section{Table 1}

\subsubsection{Wind shear}

We start with the case where near-surface dynamics are driven by a weak to moderate wind, in absence of heat exchange. In this case, the contribution of surface waves can be neglected and the wind stress $\left(\tau_{0}=\rho_{\text {air }} \cdot C_{10} \cdot U_{10}\right)$ is equal to the tangential shear stress $\left(\tau_{t}=\rho_{w a t} \cdot u_{*, w a t}{ }^{2}\right)$. The relationship between $\varepsilon$ and the sheared velocity on the water side, $u_{*, w a t}$, is then derived

175 from a law-of-the-wall scaling for the velocity profile: $\varepsilon=u_{*, w a t}^{3} / \kappa z(0)$ with $K$ being the von Kármán constant $(=0.41)$ and $z(0)$ the thickness of the diffusive boundary layer. This relationship leads to:

$k_{N B}=a_{1} \cdot\left(v u_{*, \text { wat }}^{3} / \kappa z(0)\right)^{1 / 4} S c^{-0.5}$,

The challenge is then to define $z(0)$. Tedford et al. (2014) followed an ad hoc observational approach and chose $z(0)=0.15$ $\mathrm{m}$, as the shallower depth where $\varepsilon$ was measured. In contrast, theoretical studies linked $z(0)$ to the thickness of the diffusive 180 or viscous sublayer $(\sim 0.1-1 \mathrm{~cm})$. In line with theory, we scale this layer as $z(0)=c v / u_{*, w a t}$ (Wüest and Lorke, 2003; Lorke and Peeters, 2006) with $c$ as a constant value. Taking $c=114$ (Soloviev et al., 2007), the thickness of this layer typically ranges from 0.04 to $0.14 \mathrm{~m}$ under a wind regime of 10 to $1 \mathrm{~m} \mathrm{~s}^{-1}$. We therefore modify Eq. (5) as to compute the interfacial (nobubble, NB) exchange coefficient:

$k_{N B}=a_{1} u_{*, w a t}(1 / \kappa c)^{1 / 4} S c^{-0.5}$,

185 or

$k_{N B}=a_{1}\left(\rho_{\text {air }} / \rho_{\text {wat }}\right) C_{10} U_{10}(1 / \kappa c)^{1 / 4} S c^{-0.5}$

These equations show that the SRM formulation (Soloviev et al., 2007; Read et al., 2012; Table 1 and Fig. B1) is analogous to the COAREG flux algorithm (Fairall et al., 2011), and the formulation used in Deike and Melville (2018) with the sheared 
velocity on the atmosphere side, $u_{*, a t m}$ (Table 1: DM18). Indeed, when equating the expression by Deike and Melville (2018):

with (6a), we find that the coefficient $a_{1}=0.29$ in Soloviev et al., (2007) and Read et al., (2012) is essentially equivalent to the coefficient $A_{N B}=a_{1}(\kappa c)^{-1 / 4}(1 / 600)^{1 / 2}\left(\rho_{\text {wat }} / \rho_{\text {air }}\right)^{-1 / 2} \approx 1.5 \times 10^{-4}$ in Deike and Melville (2018) (Fig. B1), which in turn was found equal to the coefficient of $A=1.5$ in Fairall et al. (2011). These results agree with Lorke and Peeters (2006) who derived a unified relation for interfacial fluxes (air-water and water-sediment) through a linear relationship of $u_{\text {,wat }}$ to $k$, especially at the bottom interface where shear is the only relevant process. Furthermore, Equation 6 has a similar (i.e., quasilinear) wind- $k$ relationship as the data-driven parameterization from VP13 but cannot explain the higher order polynomial relationship reported in CW03 and CC98.

\subsubsection{Convection}

A second source of dissipation at the surface is the convection $\left(\varepsilon_{c}\right)$ resulting from surface cooling. The combination of wind shear and free convection near a boundary is described by the Monin-Obukhov similarity theory (MOST) with a general form derived from a turbulent kinetic energy balance (Lombardo and Gregg, 1989; Tedford et al. 2014):

$\varepsilon(z)=\varepsilon_{u}(z)\left(c_{u}+c_{c}\left\lfloor\frac{z}{L_{M O}}\right\rfloor\right)$,

where $L_{M O}$ is the Monin Obukov length scale defined as $L_{M O}=u_{\text {,wat }}^{3} / \kappa B_{0}$, including $\varepsilon(z)=c_{u} \cdot \varepsilon_{u}+c_{c} \cdot \varepsilon_{c}$ in Eq. (2) that can be rearranged as:

$205 k_{N B}=a_{1}\left(\varepsilon_{u}\left(c_{u}+c_{c} \cdot B_{0} / \varepsilon_{u}\right)^{1 / 4}\right) S c^{-1 / 2}$,

$a_{1}$ ranges in the literature from 0.2 to 1.2 (Soloviev et al., 2007; MacIntyre et al., 2010; Tedford et al., 2014; Heiskanen et al. 2014; Winslow et al., 2016), $c_{u}$ from 0.84 to 1 (Winslow et al., 2016) and $c_{c}$ from 0.37 to 2.5 (Wyngaard and Coté, 1971; Tedford et al., 2014). Hereafter, we use the following set of values: $c_{u}=1$ and $c_{c}=1$. Fairall et al. (2011) used an essentially equivalent approach but formulated in terms of a Richardson number to describe the partitioning between dissipation from convection and wind shear, expressing the wind shear in terms of the air-side friction velocity: $R_{f}=B_{0} v / u_{\text {, atm }}^{4}$, which can be integrated into (9) as:

$k_{N B}=a_{1}\left(\frac{\rho_{a t m}}{\rho_{\text {wat }}}\right)^{1 / 2} u_{, a t m}\left(\frac{c_{u}}{\kappa c}\left(1+\frac{R_{f}}{R_{f, c}}\right)\right)^{1 / 4}\left(\frac{S c}{600}\right)^{-1 / 2}$,

with $R_{f, c}=\frac{c_{u} \rho_{a t m}^{2}}{c_{c} \rho_{\text {wat }}^{2} \kappa c}$. The details of this demonstration can be seen in Soloviev and Schlüssel (1994). 


\subsubsection{Wave action}

215 The effect of surface waves is commonly implemented in oceanography but barely considered in limnology. All process-based models rely on the same parameterization of energy dissipation by wind shear and convection. They however differ in how they parameterize energy dissipation by wave action and wave breaking.

The contribution of the wave action $\left(\varepsilon_{w}\right)$ is, accordingly, added as a third source of turbulence (Fig. 1). In the presence of

220 surface waves, the balance between $\tau_{t}$ and $\tau_{0}$ does not hold anymore. Therefore, Soloviev and Schlüssel (1994) added a corrective factor, $\varphi$, using the Keulegan number $\left(K e=u_{\text {,wat }}^{3} /(g v)\right)$, in order to decrease the component $\tau_{t}=\tau_{0} \cdot \varphi$ where $\varphi$ $=1 /\left(1+K e / K e_{c}\right)$, with the critical Keulegan number $\left(K e_{c}\right)$ define in Soloviev and Lukas (2006). As a result, the equation for shear-driven dissipation $\varepsilon_{u}(\mathrm{z})$ is:

$\varepsilon_{u}(z)=\frac{u_{, w a t}^{4}}{\kappa c v} \cdot \varphi^{2}$,

225 Following this step, the turbulent kinetic energy dissipation rate from wave action $\left(\varepsilon_{w}\right)$ is added and defined with the Keulegan number by Soloviev et al. (2007) as:

$\varepsilon_{w}=\alpha_{W}\left(\frac{3}{B S_{q}}\right)^{1 / 2} \frac{\left(K e / K e_{C r}\right)^{3 / 2}}{\left(1+K e / K e_{C r}\right)^{3 / 2}} \frac{u_{\text {wat }} g}{0.062 \kappa C_{T}\left(2 \pi A_{W}\right)^{3 / 2}} \frac{\rho_{a t m}}{\rho_{w a t}}$,

where $C_{T}=\left(z_{0} / H_{S}\right) . z_{0}$ is the surface roughness scale from the water side and the $C_{T}$ value is set as a constant at 0.6 (More details in Soloviev et al., 2007). This definition does not hold for closed basins because, in the case of incompletely developed waves, the dissipation of energy from wind shear transmitted to the waves is not fully redistributed in the water body (Simon, 1997). Hence, for the application in Lake Geneva, we followed Terray et al. (1996) who defined a varying $C_{T}$ :

$C_{T}=1.38 \cdot 10^{-4}\left(\frac{U_{10}}{C_{p}}\right)^{2.66}$,

where $C_{p}$ is the peak speed of the wave spectrum defined in Deike and Melville (2018) according to Toba (1972, 1978). This leads to $C_{T} \ll<1$. This allows to increase the effect of $\varepsilon_{w}$ (inversely proportional to $C_{T}$ in Eq. 12) on $k$. Here, we used this

235 formulation to adapt the $S 07$ ocean model for a large lake (closed basin). Henceforth we refer to the adapted uncalibrated and calibrated models as SD2O and SD20-fit, respectively (Table 1). Finally, these three terms of $\varepsilon\left(\varepsilon_{u}, \varepsilon_{c}, \wedge \varepsilon_{w}\right)$ can be added before computing the SRM (Eq. 2) for determining $k$-no bubble $\left(k_{\mathrm{NB}}\right)$.

\subsubsection{Bubble enhancement}

Additional deviations from the linear relationship to $U_{10}$ are explained by the gas transfer resulting from bubbles and sprays 240 during wave breaking. This mechanism is accounted for by adding a $k$-bubble $\left(k_{\mathrm{B}}\right)$ term to the already mentioned $k_{\mathrm{NB}}$. Soloviev et al. (2007) used the empirical $k$-bubble parameterization from Woolf et al. (1997): 
$k_{B}=W \frac{2450}{o_{S}\left(1+\frac{1}{\left(14 O_{S} S c^{-0.5}\right)^{1 / 1.2}}\right)^{1.2}}$,

where $W$ is the fractional whitecap coverage only expressed as a function of wind $\left(3.84 \cdot 10^{-6} \cdot U_{10}^{3.41}\right.$ and $O_{\text {s }}$ is Ostwald gas solubility. This formulation does not take wave height into account (Fig. B1). Nevertheless, a recent study (Deike and Melville,

245 2018) performed a new numerical process-based parameterization for gas transfer velocity from bubble enhancement considering $H_{\mathrm{s}}$ through the following equation:

$k_{B}=\frac{A_{B}}{O_{S}} u_{*, a t m}^{5 / 3}\left(g H_{s}\right)^{2 / 3}\left(\frac{S c}{600}\right)^{-1 / 2}$,

where $A_{B}$ is an empirical factor with dimension $\left(=10^{-5} \mathrm{~m}^{-2} \mathrm{~s}^{2}\right)$ and $O_{s}$ defines by the ideal gas constant $(R)$, the surface water temperature $\left(T_{0}\right)$ and, $\mathrm{CO}_{2}$ solubility coefficient in freshwater $(\alpha)$ (Reichl and Deike, 2020). Then, the gas transfer velocity is expressed as a sum of no-bubble $k_{\mathrm{NB}}$ and bubble $k_{\mathrm{B}}$ components (Table 1: S07, DM18, SD20, and SD20-fit) following Keeling (1993) and Woolf et al. (1997, 2005). Our adapted models modified from SO7 (SD20 and SD20-fit) include a refined parameterization of the wave action term $\varepsilon_{w}$ along with the bubble term from DM18 (SD20 and SD20-fit). In addition, for the model SD20-fit, the $a_{1}$ parameter of Eq. (2) and the $A_{B}$ parameter of Eq. $(15)$ were fitted to the $k_{600}$ observations $\left(a_{1}=0.33\right.$ and $A_{B}=310^{-5} \mathrm{~m}^{-2} \mathrm{~s}^{2}$ ).

With this review of existing and adapting parameterizations, we show that (i) there is a discrepancy between SRM-based model with shear stress as the only energy source and empirical parameterizations with polynomial (order > 1) wind-based relationship. Such a discrepancy is tentatively resolved by adding the effect of convection and surface waves. (ii) We further highlight that most fitting parameters from the different SRM-based models are in good agreement. (iii) We finally recall that it is possible to provide a unifying parameterization of $k$ with SRM model including wind shear, wind-induced waves, and convection with only a few input parameters such as $U_{10}, B_{0}$, and Fetch.

\section{Results}

\subsection{Observed and predicted $k$}

After quality check, our dataset contains 94 discrete $\mathrm{CO}_{2}$ flux observations. We first assess the representativeness of our sampling by comparing the survey-specific and annual distributions of the three main inputs for $k$-models: $U_{10}$ (all models), $B_{0}$ during convective periods $\left(T 14, S 07, S D 20 \& S D 20\right.$-fit) and $H_{\mathrm{s}}(S 07$, DM18, SD20 \& SD20-fit) (Fig. 3; Temporal evolution of these three terms in Fig. C1). From $13^{\text {th }}$ June 2019 to $12^{\text {th }}$ June 2020 , the average wind speed over Lake Geneva is $2.9 \mathrm{~m} \mathrm{~s}^{-}$

${ }^{1}$ with a mode at $2.5 \mathrm{~m} \mathrm{~s}^{-1}$; very low wind speeds $\left(<1 \mathrm{~m} \mathrm{~s}^{-1}\right)$ are encountered $12 \%$ of the year, while high- $\left(>5 \mathrm{~m} \mathrm{~s}{ }^{-1}\right.$ to very high $>10 \mathrm{~m} \mathrm{~s}^{-1}$ ) wind events represent $15 \%$ and $2 \%$ of the year, respectively. The sampling surveys covered the full annual range of $U_{10}$. Average and modal values of $B_{0}$ over the year are close to $0.2510^{-7} \mathrm{~m}^{2} \mathrm{~s}^{-3}$. However, the sampling covered only 
the lowest $50 \%$ of the annual distribution and under-samples conditions of potentially strong convection. Considering that the dissipation by buoyancy flux, as parameterized in the process-based models, is already well known in the literature and that it is not the central point of our study, we posit that the under-sampling of $B_{0}$ is therefore not expected to significantly affect our analysis. The predicted modal $H_{\mathrm{s}}$ value is $0.15 \mathrm{~m}$ over the year. Events of high $H_{\mathrm{s}}(>0.4 \mathrm{~m})$ represent $6 \%$ of the year, with a maximum $H_{\mathrm{s}}$ of $1.1 \mathrm{~m}$. As for $U_{10}$, the surveys covered the full range of annual $H_{\mathrm{s}}$.

\section{Figure 3}

Observationally based $k_{600}$ are shown with their error bars corresponding to the uncertainties of the $\mathrm{pCO}_{2}$ in air and in water $( \pm 50 \mathrm{ppm})$ in Fig. 4a. We notice that all the measurements with a wave height $>0.4 \mathrm{~m}$ were observed for wind speeds $>5 \mathrm{~m}$ $\mathrm{s}^{-1}$ and the corresponding $k_{600}$ are located above the linear function (i.e., from a linear regression against wind shear velocity; Fig. B1) scaling $k_{600}$ to $u_{*}$ (i.e., first order relationship) We then compare the $k_{600}$ observed during the specific surveys to the values computed with all $k_{600}$ models throughout the annual cycle, in relation to $U_{10}$ (Fig. $4 \mathrm{~b}-\mathrm{c}$ ). Table 2 provides the rootmean square errors (RMSE) for all model estimates compared to $k_{\mathrm{obs}}$ during the flux surveys, (i) for the full dataset (All Wind), and split (ii) for low wind $\left(<5 \mathrm{~m} \mathrm{~s}^{-1}, \mathrm{LW}\right)$ and (iii) strong wind conditions $\left(\geq 5 \mathrm{~m} \mathrm{~s}^{-1}, \mathrm{SW}\right)$. The three empirical wind-based models only depend on wind (Fig. 4b). Both CC98 and CW03 were originally calibrated for small lakes, using a mass balance

calibration method (Table 1). However, they lead to divergent gas transfer velocities, particularly above $5 \mathrm{~m} \mathrm{~s}^{-1}$, illustrated by a RMSE for SW as high as $22.8 \mathrm{~cm} \mathrm{~h}^{-1}$ for $C C 98$ while $C W 03$ performs better (RMSE SW $=12.8 \mathrm{~cm} \mathrm{~h}^{-1}$ ). Furthermore, both models underestimate $k_{600}$ at low wind (Fig. 4a), with a higher deviation for $C W 03$ (Table 2). The $k$ values predicted by VP13 are closer to those of the process-based models that explicitly integrate wave actions (SO7 and DM18) (Fig. 4bc), demonstrating that lake size integration in the empirical model captures at least part of the wave action on $k$. Performances of VP13 at strong winds (RMSE SW $=12.7 \mathrm{~cm} \mathrm{~h}^{-1}$ ) were better than those of the ocean-derived models integrating surface waves (RMSE SW = 13-15.9 $\mathrm{cm} \mathrm{h}^{-1}$ ). However, VP13 shows a positive offset during calm periods, along with the highest RMSE of the set of models at low wind speed (Fig. 4b; Table 2).

\section{Figure 4}

The process-based models (Fig. $4 \mathrm{c}$ ) provide different $k_{600}$ values for a given wind speed, owing to the integration of additional environmental components (i.e., the varying drag coefficient, the convective mixing in $R 12$ and $T 14$ as well as the effect of waves in SO7, DM18, SD20 and SD20-fit). All process-based models are similar at low winds as they share a common physical basis for parameterization of wind shear and convection. Therefore, they lead to similar RMSE (2.9-3.5 $\left.\mathrm{cm} \mathrm{h}^{-1}\right)$ under such conditions, where surface waves are negligible (Table 2). Divergences occur at higher wind speeds. T14, initially developed for small lakes with limited wind exposure, performed the worst (RMSE: $19.8 \mathrm{~cm} \mathrm{~h}^{-1}$ ). This increased $k$-underestimation at high winds can be attributed to (i) dissipation by wave action and bubble formation not considered (in R12 and T14), and (ii) to the use of a constant $z(0)=0.15 \mathrm{~m}$ in the $T 14$ model (Eq. 5). This approximation of the diffusive layer is consistent with low wind speed but is almost one order of magnitude too large under strong wind speed. Other process-based models, designed for greater wind range $\left(>10 \mathrm{~ms}^{-1}\right.$ ), integrate surface waves and, as a result, lead to better estimates than $R 12$ and T14 (RMSE: $\left.10.4-15.9 \mathrm{~cm} \mathrm{~h}^{-1}\right)$. However, the ocean wave model of DM18 shows lower performances at strong winds than CW03 and VP13 
305 (Fig. 4bc). Finally, the specific fit parameterization of the SD20-fit model improves the performance at high wind speeds by $\sim 30 \%\left(\right.$ RMSE $\left.=10.5 \mathrm{~cm} \mathrm{~h}^{-1}\right)$, outperforming all the other methods.

\section{Table 2}

\subsection{Surface wave integration}

We herein scrutinize how those varying parameterizations ultimately alter the shape of relationship between $k_{600}$ and $U_{10}$. In $R 12$ (Fig. 5a), wind is only included through wind shear, resulting in a linear relationship between $k_{600}$ and $U_{10}$, as already anticipated. Adding the wave action (no bubble) through the $S 07$ parameterization (Fig. 5b) does not lead to any significant departure from the minimal $R 12$ model. Adapting wave action by decreasing $C_{T}$ (for the no-bubble term) leads to a departure from the wind shear linear relationship for $H_{s}>0.4 \mathrm{~m}$ (Fig. 5c).

315 Then, adding the $k$ bubble term related to wave breaking of $D M 18$ further increases this deviation from the linear $k_{600}-U_{10}$ relationship but also scatters $k_{600}$ estimates for a given $U_{10}$ (Fig. $5 \mathrm{~d}$ ). Finally, the fitting with observationally based $k_{600}$ improves the estimation for strong wind (Fig. 5e; Table 2). Given the range of wind fetch from $\sim 0.5 \mathrm{~km}$ to $\sim 30 \mathrm{~km}$, the contribution of waves varies for a given wind speed depending on the fetch, as evidenced by the scattering of the parameterized $k_{600}$ for a given $U_{10}$ (Fig. 5f). A significant modification of $k_{600}$ by wave action and wave breaking occurs for a fetch length $>15 \mathrm{~km}$ and $U_{10}>5 \mathrm{~m} \mathrm{~s}^{-1}$ (Fig. 5f), in the case of Lake Geneva, generating wave of $H_{s}>0.4 \mathrm{~m}$ (Fig. 5e).

\section{Figure 5}

As compared to $k_{600}$ estimated by $R 12$ (Fig. 5a), the $S D 20$ and SD20-fit models provide $k$ estimates that are 20-50 \% higher for $U_{10}=10 \mathrm{~m} \mathrm{~s}^{-1}$, respectively, and 40-70\% higher for $U_{10}=15 \mathrm{~m} \mathrm{~s}^{-1}$. Therefore, adapting the surface waves, through the change of the wave action for incompletely developed waves and the fitting to observed data encountered in local lake conditions, leads to better performances of SD20 models. SD20-fit reached the lowest RMSE at all wind speeds and is thereafter used as a reference for the modelling of the annual gas transfer velocities.

\subsection{Annual cumulative gas transfer velocity and the effect of extreme conditions}

We show above that models accounting for surface waves better represent the non-linear increase in $k_{600}$ at high winds. Because high-wind events remain rare, we test whether a better representation of $k_{600}$ during rare, high-wind events affects the local estimates of $k_{600}$ over a full year. To this end, cumulative sums of hourly $k_{600}$ were computed over a full annual cycle ( $13^{\text {th }}$ June $2019-12^{\text {th }}$ June 2020) for all $k$-models (Fig. 6). The annual dynamics such as the annually averaged $k_{600}$ were compared using SD20-fit as a new reference model.

\section{Figure 6}

Cumulated $k_{600}$ computed for SD20-fit shows some episodic steep increases between December and March, due to the winterly

335 prevalence of high wind events (winter average wind speed, $3.25 \mathrm{~m} \mathrm{~s}^{-1}$, was greater than the summer mean, $2.55 \mathrm{~m} \mathrm{~s}^{-1}$, by 25 $\%$ ) and greater significant wave height (winter average wave height, $0.15 \mathrm{~m}$, greater than the summer value, $0.10 \mathrm{~m}$, by $50 \%$ ) 
(Fig. C1). The average hourly $k_{600}$ by the SD20-fit model is $7.3 \pm 7.4 \mathrm{~cm} \mathrm{~h}^{-1}$ (mean \pm se, Fig. 6a). Periods of high-winds, although accounting for $15 \%$ of data points, contribute $44 \%$ of annually cumulated- $k_{600}$ in the SD20 and SD20-fit models (Fig. 6b), while the periods of high waves $\left(H_{\mathrm{s}} \geq 0.4 \mathrm{~m}\right)$ accounting for only $6 \%$ of data points, contribute to more than $20 \%$ 340 of annually cumulated- $k_{600}$. The wind-based models are those for which cumulative $k_{600}$ diverges the most from the SD20-fit reference model, with the lowest annual averaged $k_{600}$ for $C C 98$ and $C W 03(3.9 \pm 2.7$ and $4.8 \pm 9.3$ respectively) and the highest for VP13 $(9.9 \pm 6.1)$. These divergences arise from the low performances of these models at low wind regimes (Fig. $4 a, 6 b$; Table 2), which represent $85 \%$ of annual data-points. All the other process-based models have relative dynamics of cumulative $k_{600}$ similar to that of the SD20-fit model and end up with annually averaged $k_{600}$ that are $15 \%$ lower than for the SD20-fit. The representation of $k_{600}$ at low wind speeds is similar for all process-based models, and the divergence arises from the representation of the rarer high wind speed episodes, which contribute to $43-46 \%$ of annual cumulative $k_{600}$ (Fig. $6 \mathrm{~b}$ ).

\section{Discussion}

The history of $k$-models, simulating the gas transfer velocity for surface waters, dates back from the early 1990's. $k$-models have been developed and tested in small lakes sheltered from winds (e.g., Crusius and Wanninkhof, 2003; Tedford et al., 2014), large lakes under low to moderate wind speed (Vachon and Prairie, 2013), and oceans (e.g., Soloviev et al., 2007; Fairall et al., 2011; Esters et al., 2017; Deike and Melville, 2018). While the effects of surface waves on $k$ can be neglected in small lakes, we question herein whether this assumption holds for large lakes such as Lake Geneva, in which surface waves are frequently observed (Fig. 2; Fig. C1). We evaluated the performance of different experimental-based and process-based models to estimate $k_{600}$ in the large Lake Geneva. We show that integrating the effect of wave formation at high wind speeds and long fetch better represents the sharp increase of the $k_{600}$ values during such episodic windy events.

\subsection{Choice of $k$-models}

Wind-based models have been long known for misestimating $k_{600}$ at low wind speeds (Eugster et al., 2003; MacIntyre et al., 2010; Erkkilä et al., 2018). Consistently, wind-based models showed the lowest performances for Lake Geneva, especially at low wind speeds (CW03 and VP13), which resulted in large discrepancies in annually averaged and cumulative $k_{600}$ over the full year. They are however easy to compute, require few inputs (only $U_{10}$ ) and, remain by far the most used to estimate lakes $\mathrm{CO}_{2}$ emissions worldwide (e.g., Raymond et al. 2013). One solution to increase the performance of wind-based models is to revise calibration at each new site (Klaus and Vachon, 2020). Another possibility is to broadly adopt process-based models. The presented process-based models require input data that are today more easily accessible: wind speed, heat flux and wind fetch (i.e., distances from the shore) routinely acquired at high-frequency in many lakes. The development of R packages such as Lake Metabolizer (Winslow et al., 2016) in which the calculations of process-based models are implemented, also alleviates their computational difficulty. Both increased data availability and computational tools should foster the use of process-based $k$-models, which hold great potential to obtain more accurate global $k_{600}$ estimates. 
The analysis of the models adapted from the existing literature to account for the effect of waves, SD2O and SD20-fit (Fig. 5de-f), showed that the wave contribution to $k$ becomes significant for $H_{\mathrm{s}}>0.4 \mathrm{~m}$, corresponding, for Lake Geneva, to winds blowing at $5 \mathrm{~m} \mathrm{~s}^{-1}$ from the southwest where the fetch length is maximal (>15 km) with respect to the measurement site. A significant to the gas transfer velocity by surface waves is expected in lakes where $H_{\mathrm{s}}>0.4 \mathrm{~m}$ is not infrequent. Wave heights beyond this threshold value of $H_{\mathrm{s}}$ are frequently encountered in lakes of similar or greater sizes than Lake Geneva (6\% of annual time in Lake Geneva). In the Great Lakes of North America, Hubertz et al. (1991) showed that the mean wave height of all these lakes were $>0.4 \mathrm{~m}$ in summer and close to $1 \mathrm{~m}$ in winter with a maximum of up to $5 \mathrm{~m}$. $H_{\mathrm{s}}>0.4 \mathrm{~m}$ can also form over elongated lakes of smaller size, such as smaller Swiss Lakes (e.g., Lake Neuchâtel, Lake Bienne) (Amini et al., 2017). Since SD20-fit is a process-based model integrating the four main processes in a mathematically coherent way, we would expect that it can be applied to such lakes experiencing $H_{\mathrm{s}}>0.4 \mathrm{~m}$ and improves the accuracy of $k$ estimates. Because waves can physically damage in-shore and off-shore infra-structures, many large lakes benefit from wave forecasts. $H_{\mathrm{s}}$-data from those forecasting systems (e.g., National Data Buoy Centre - NOAA, Wave Atlas from SwissLakes.net; Amini et al., 2017) could allow testing whether the SD20-fit models can be applied to those lakes and whether $k_{\mathrm{NB}}$ and $k_{\mathrm{B}}$ through $a_{1}$ and $A_{b}$ need to be recalibrated or fitted to the local context if flux measurement data are available, as for this study. Energy dissipation during high-wave events increases the gas-transfer velocity well beyond the linear relationship derived for wind shear alone. We therefore expect that computed gas fluxes at the air-water interface should be significantly improved by the integration of surface waves into the $k$-models.

\subsection{Implication of four components on the annual $k$ estimation and the annual $\mathrm{CO}_{2}$ fluxes}

\subsubsection{Seasonal distribution of $k_{\mathrm{CO} 2}$}

Converting $k_{600}$ to $k_{\mathrm{CO} 2}$ using the Schmidt number (Wanninkhof, 1992) highlights the importance of water temperature in gas exchange dynamics. Indeed, the seasonal distribution of the cumulative $k_{600}$ is $\sim 20 \%$ and $\sim 30 \%$ for the warm (spring and summer) and cold (autumn and winter) seasons, respectively. Once the temperature-effect accounted for, this distribution increases to $26.1 \%$ for the summer and decreases to $24.9 \%$ for the winter but remains unchanged for spring and autumn. While R12 only use wind shear and convective terms, the selected process-based model (SD2O-fit) allows a decomposition into the four main drivers of the gas transfer velocity, hence paving the way to a better understanding of the implication of these processes throughout an annual cycle.

\section{Figure 7}

Wind shear remains the dominant component of the gas exchange velocity over the different seasons (Fig. 7a). The annual contribution of surface waves (wave action and bubble formation) is limited to 9 to $10 \%$ of the cumulative $k$ in Autumn and Winter. The contribution of buoyancy flux at surface to $k$ is even smaller for both models (R12 and SD2O-fit) at this seasonal scale. Yet, both the buoyancy flux and the surface waves can significantly increase $k$ during episodic events, during which 
they can contribute disproportionately to $k$ at hourly (up to $80 \%$ for convection) and daily (up to $25 \%$ for surface waves) time scales (Fig. 7b). Several studies have emphasized the disproportionate contribution of episodic mixing events on annual flux, bringing $\mathrm{CO}_{2}$ back to lake surfaces such as after ice break in dimictic lakes (Karlsson et al., 2013; Finlay et al., 2019) or during fall mixing on a eutrophic deep lake (Reed et al., 2018). Process-based $k$-models integrating both the buoyancy flux and the wind-induced waves offer the opportunity to mechanistically investigate how much those episodic events contribute to annual emissions through short-term modifications of the gas exchange velocity.

\subsubsection{Consequences on the choice of $k$-model on the monthly to annual $\mathrm{CO}_{2}$ flux estimation}

Monthly fluxes were computed based on $k$-estimates from the different models at hourly timestep and the monthly average of water temperature and recorded $\mathrm{pCO}_{2}$ at the lake surface (OLA-IS, AnaEE-France, INRAE of Thonon-les-Bains, CIPEL, Rimet et al., 2020; Perga et al., 2016) as well as a constant $\mathrm{pCO}_{2}$ in the atmosphere (400 $\mu \mathrm{atm}$ ). As predicted by the Fick's law, the highest outgassing fluxes occur in fall and winter, when water mixing brings $\mathrm{CO}_{2}$ up to the lake surface, while low up-taking gas fluxes occur in spring and summer, when primary production depletes surface $\mathrm{CO}_{2}$ below saturation. However, annual estimates of net $\mathrm{CO}_{2}$ outgassing vary from 14.7 to $37.1 \mathrm{mmolC} \mathrm{m}^{-2} \mathrm{~d}^{-1}$ (Table 3) depending on the $k$-model used for computation. Consistently, differences between model estimates are relatively low in summer since both the $\Delta p \mathrm{CO}_{2}$ gradient (100-200 $\mu \mathrm{atm})$ and wave occurrence are limited. Estimated fluxes are strongly dependent on the chosen $k$-model in winter

415 when both $\triangle \mathrm{pCO}_{2}(475 \mu \mathrm{atm})$ and surface waves occurrence are higher (Table 3; Fig.7). Therefore, while high wave events represent only $6 \%$ of the total surface waves occurrence $\left(H_{\mathrm{s}}>0.4 \mathrm{~m}\right)$, an incomplete consideration and description of their contribution may lead to an annual flux underestimation of about 20-25\%. The weak contribution of convection is at odds with observations in small lakes, but not unexpected, since large lakes are exposed to stronger winds, such that wind sheardriven $\varepsilon_{u}$ often outpaces convectively driven, $\varepsilon_{c}$ (Read et al, 2012). However, the limited impact of the buoyancy flux on $k$ does not rule out its contribution to $\mathrm{CO}_{2}$ exchange. Indeed, convective mixing plays a central role in the deepening of the mixed layer allowing the export of the $\mathrm{CO}_{2}$ stored in the hypolimnion towards the surface during the cold period and thereby controlling the $\mathrm{pCO}_{2}$ gradient (Zimmerman et al, 2020) and the observed wintertime outgassing. Altogether, both surface oversaturated $\mathrm{CO}_{2}$ concentrations (as a result of convective mixing) and wind-induced waves are more relevant in fall and wintertime for the monomictic Lake Geneva, leading to most of the annual outgassing during this season (Table 3). As for many monomictic lakes, these seasons drive most of the annual $\mathrm{CO}_{2}$ budget of Lake Geneva (Perga et al, 2016), while they usually correspond to those where direct measurements are the scarcest. An improved quantification of $k$-values through SRMmodels including wind-induced waves should contribute to refining the overall estimation of large lakes contribution to regional $\mathrm{CO}_{2}$ emissions.

Table 3 


\section{Conclusion}

Investigations of the four main processes generating the gas transfer velocity in the large Lake Geneva demonstrated the importance of considering surface waves during episodic windy events responsible for more than $44 \%$ of annual cumulated $k_{600}$. The in-depth study of the behaviour of the process-based models has enabled to underscore their consistent predictions at low and strong wind, especially considering the new combination and adaptation model, SD2O-fit. This last model significantly improves the estimation of $\mathrm{CO}_{2}$ flux when these three thresholds appear in the field: $U_{10}>5 \mathrm{~ms}^{-1}$, Fetch $>15 \mathrm{~km}$, and $H_{s}>0.4$ $\mathrm{m}$, making it applicable in a wide range of lake sizes. Furthermore, SD20-fit is assembled on solid theoretical bases coming from limnological and oceanic literature and allows to analyse the distribution of these four main terms $\left(k_{\mathrm{u}}, k_{\mathrm{c}}, k_{\mathrm{w}}\right.$, and $\left.k_{\mathrm{b}}\right)$ across a variety of time scales depending on the kind of study.

440 Noteworthily, $S D 20$ was built on the basis of a single measurement point on the lake, just as for most of the existing $k$ models. Therefore, the question of the extrapolation of the model to the whole of the lake remains essential. We assume three ways of different complexities: (i) estimate an average fetch value depending on the wind direction and the geometry of the lake, (ii) discretize the lake into a few parts according to the complexity of its geometry and direction of the prevailing winds, and (iii) discretize the lake into a large number of pixels based on 2D or 3D wind models available in some countries in order to estimate

445 gas transfer velocity and gas fluxes at a finer spatial scale. Nevertheless, the question of the spatial variability of the $\Delta C \mathrm{O}_{2}$ is still open and difficult to analyse at high frequency in large lakes.

To conclude, this study sheds light on the complexity of large lakes located at the interface between small, sheltered lakes and the open oceans, thus experiencing a combination of processes relevant for both small and large systems. The possibility of using process-based models in a fairly simple way with few inputs to improve the precision of the gas transfer velocity and therefore the gas flux should be supported in future research. In addition, this approach is very promising regarding long-term trends of $\mathrm{CO}_{2}$ emissions from lakes, as well as a finer estimation of fluxes during more intense episodic events.

\section{Appendix A}

Figure A1

455 Figure A2

Figure A3

\section{Appendix B}

\section{Figure B1}




\section{Appendix C}

\section{Figure C1}

Data availability. Water temperature, buoyancy flux at surface, and meteorological data are available in the datalakes - Open research data publishing platform (https://www.datalakes-eawag.ch). Water $\mathrm{CO}_{2}$ concentration and $\mathrm{CO}_{2}$ flux measurements are available upon request from the first author.

Author contribution. PP, MEP, and DB designed the study. PP, BFC, NE, and TL collected field data and carried out data pre-processing. PP developed the model code and performed the simulation with contribution from DB. PP, MEP, and DB drafted the manuscript and all co-authors contributed to the final submitted manuscript.

Competing interests. The authors declare that they have no conflict of interest.

Acknowledgements. We would like to thank the entire team from LéXPLORE platform, for their administrative and technical support and for LéXPLORE core dataset. We also acknowledge LéXPLORE five partner institutions: Eawag, EPFL, University of Geneva, University of Lausanne and CARRTEL (INRAE-USMB). This study was supported by

475 CARBOGEN project (SNF 200021_175530) linked to LéXPLORE project (SNF R'Equip, P157779). The authors thanks Sébastien Lavanchy, chief technical officer (APHYS-EPFL) and Aurélien Ballu, member of the technical pool (IDYST-UNIL) of LéXPLORE platform for their technical and field supports. B. F. C. was supported by the European Union's Horizon 2020 research and innovation program under the Marie Skłodowska-Curie grant agreement No. 834330 (SO-CUP).

\section{References}

480 Amini, A., Dhont, B., and Heller, P.: Wave atlas for Swiss lakes: modeling design waves in mountainous lakes, J. Appl. Wat. Eng. Res., 5, 103-113, https://doi.org/10.1080/23249676.2016.1171733, 2017.

Bastviken, D., Sundgren, I., Natchimuthu, S., Reyier, H. and Gålfalk, M.: Technical Note: Cost-efficient approaches to measure carbon dioxide $\left(\mathrm{CO}_{2}\right)$ fluxes and concentrations in terrestrial and aquatic environments using mini loggers, Biogeosciences, 12, 3849-3859, https://doi.org/10.5194/bg-12-3849-2015, 2015.

485 Borges, A. V., Vanderborght, J.-P., Schiettecatte, L.-S., Gazeau, F., Ferron-Smith, S., Delille, B. and Frankignoulle, M.: Variability of the gas transfer velocity of $\mathrm{CO}_{2}$ in a macrotidal estuary (the Scheldt), Estuaries, 27, 593-603, https://doi.org/10.1007/BF02907647, 2004.

Carter, D. J. T.: Prediction of wave height and period for a constant wind velocity using the JONSWAP results. Ocean Eng., 9, 17-33, https://doi.org/10.1016/0029-8018(82)90042-7, 1982. 
Cole, J. J., Bade, D. L., Bastviken, D., Pace, M. L., \& de Bogert, M. V.: Multiple approaches to estimating air-water gas exchange in small lakes, Limnol. Oceanogr.: Methods, 8, https//doi.org/10.4319/lom.2010.8.285, 2010.

Cole, J. J., Prairie, Y. T., Caraco, N. F., McDowell, W. H., Tranvik, L. J., Striegl, R. G., Duarte, C. M., Kortelainen, P., Downing, J. A., Middelburg, J. J. and Melack, J.: Plumbing the Global carbon cycle: Integrating inland waters into the terrestrial carbon budget, Ecosystems, 10, 172-185, https://doi.org/10.1007/s10021-006-9013-8, 2007.

Cole, J. J. and Caraco, N. F.: Atmospheric exchange of carbon dioxide in a low-wind oligotrophic lake measured by the addition of $\mathrm{SF}_{6}$, Limnol. Oceanogr., 43, 647-656, https://doi.org/10.4319/lo.1998.43.4.0647, 1998.

Crusius, J. and Wanninkhof, R.: Gas transfer velocities measured at low wind speed over a lake, Limnol. Oceanogr., 48, 10101017, https://doi.org/10.4319/lo.2003.48.3.1010, 2003.

Danckwerts, P. V.: Significance of liquid-film coefficient in gas absorption, Ind. Eng. Chem., 43, 1460-1467, https://doi.org/10.1021/ie50498a055, 1951.

Deike, L. and Melville, W. K.: Gas transfer by breaking waves, Geophys. Res. Lett., 45, 482-492, https://doi.org/10.1029/2018GL078758, 2018.

Dugan, H. A., Woolway, R. I., Santoso, A. B., Corman, J. R., Jaimes, A., Nodine, E. R., Patil, V. P., Zwart, J. A., Brentrup, J. A., Hetherington, A. L., Oliver, S. K., Read, J. S., Winters, K. M., Hanson, P. C., Read, E. K., Winslow, L. A. and Weathers,

505 K. C.: Consequences of gas flux model choice on the interpretation of metabolic balance across 15 lakes, Inland Waters, 6, 581-592, https://doi.org/10.1080/IW-6.4.836, 2016.

Engel, F., Farrell, K. J., McCullough, I. M., Scordo, F., Denfeld, B. A., Dugan, H. A., de Eyto, E., Hanson, P. C., McClure, R. P., Nõges, P., Nõges, T., Ryder, E., Weathers, K. C. and Weyhenmeyer, G. A.: A lake classification concept for a more accurate global estimate of the dissolved inorganic carbon export from terrestrial ecosystems to inland waters, The Science of Nature, 510 105, https://doi.org/10.1007/s00114-018-1547-z, 2018.

Erkkilä, K.-M., Ojala, A., Bastviken, D., Biermann, T., Heiskanen, J. J., Lindroth, A., Peltola, O., Rantakari, M., Vesala, T. and Mammarella, I.: Methane and carbon dioxide fluxes over a lake: comparison between eddy covariance, floating chambers, and boundary layer method, Biogeosciences, 15, 429-445, https://doi.org/10.5194/bg-15-429-2018, 2018.

Esters, L., Landwehr, S., Sutherland, G., Bell, T. G., Christensen, K. H., Saltzman, E. S., Miller, S. D., \& Ward, B.:

515 Parameterizing air-sea gas transfer velocity with dissipation: Dissipation-based k-parametrization. J. Geophys. Res.-Oceans, 122, 3041-3056. https://doi.org/10.1002/2016JC012088, 2017.

Eugster, W., Kling, G. W., Jonas, T., McFadden, J. P., Wüest, A., MacIntyre, S. and Chapin, F. S.: $\mathrm{CO}_{2}$ exchange between air and water in an Artic Alaskan and midlatitude Swiss lake: Importance of convective mixing, J. Geophys. Res., 108, https://doi.org/10.1029/2002JD002653, 2003.

520 Fairall, C. W., Yang, M., Bariteau, L., Edson, J. B., Helmig, D., McGillis, W., Pezoa, S., Hare, J. E., Huebert, B. and Blomquist, B.: Implementation of the Coupled Ocean-Atmosphere Response Experiment flux algorithm with $\mathrm{CO}_{2}$, dimethyl sulfide, and $\mathrm{O}_{3}$, J. Geophys. Res., 116, https://doi.org/10.1029/2010JC006884, 2011.

Finlay, K., Vogt, R. J., Simpson, G. L. and Leavitt, P. R.: Seasonality of $\mathrm{pCO}_{2}$ in a hard-water lake of the northern Great 
Plains: The legacy effects of climate and limnological conditions over 36 years, Limnol. Oceanogr., 64, 118-129, https://doi.org/10.1002/lno.11113, 2019.

Frost, T. and Upstill-Goddard, R. C.: Meteorological controls of gas exchange at a small English lake, Limnol. Oceanogr., 47, 1165-1174, https://doi.org/10.4319/lo.2002.47.4.1165, 2002.

Guérin, F., Abril, G., Serça, D., Delon, C., Richard, S., Delmas, R., Tremblay, A. and Varfalvy, L.: Gas transfer velocities of $\mathrm{CO}_{2}$ and $\mathrm{CH}_{4}$ in a tropical reservoir and its river downstream, J. Marine Syst., 66, 161-172, 530 https://doi.org/10.1016/j.jmarsys.2006.03.019, 2007.

Hasselmann K., Barnett T.P., Bouws, E., Carlson, H, Cartwright D.E., et al.: Measurements of wind-wave growth and swell decay during the Joint North Sea Wave Project (JON- SWAP), Dtsch. Hydrog. Z. Suppl. A, 8, 95 pp., 1973.

Heiskanen, J. J., Mammarella, I., Haapanala, S., Pumpanen, J., Vesala, T., MacIntyre, S. and Ojala, A.: Effects of cooling and internal wave motions on gas transfer coefficients in a boreal lake, Tellus B, 66, https://doi.org/10.3402/tellusb.v66.22827, 2014.

Hubertz, J. M., Driver, D. B., and Reinhard, R. D.: Wind waves on the Great Lakes: A 32 year hindcast. J. Coastal Res., 7, 945-967. ISSN 0749-02208, 1991.

Huotari, J., Ojala, A., Peltomaa, E., Nordbo, A., Launiainen, S., Pumpanen, J., Rasilo, T., Hari, P. and Vesala, T.: Long-term direct $\mathrm{CO}_{2}$ flux measurements over a boreal lake: Five years of eddy covariance data, Geophys. Res. Lett., 38, 540 https://doi.org/10.1029/2011GL048753, 2011.

Karlsson, J., Giesler, R., Persson, J. and Lundin, E.: High emission of carbon dioxide and methane during ice thaw in high latitude lakes, Geophys. Res. Lett., 40, 1123-1127, https://doi.org/10.1002/grl.50152, 2013.

Katul, G. and Liu, H.: Multiple mechanisms generate a universal scaling with dissipation for the air-water gas transfer velocity, Geophys. Res. Lett., 44, 1892-1898, https://doi.org/10.1002/2016GL072256, 2017.

545 Katul, G., Mammarella, I., Grönholm, T. and Vesala, T.: A structure function model recovers the many formulations for airwater gas transfer velocity, Water Resour. Res., 54, 5905-5920, https://doi.org/10.1029/2018WR022731, 2018.

Keeling, R. F., Najjar, R. P., Bender, M. L. and Tans, P. P.: What atmospheric oxygen measurements can tell us about the global carbon cycle, Global Biogeochem. Cycles, 7(1), 37-67, https://doi.org/10.1029/92GB02733, 1993.

Klaus, M. and Vachon, D.: Challenges of predicting gas transfer velocity from wind measurements over global lakes, Aquat.

550 Sci., 82, https://doi.org/10.1007/s00027-020-00729-9, 2020.

Lamont, J. C. and Scott, D. S.: An eddy cell model of mass transfer into the surface of a turbulent liquid, AIChE J., 16, 513519, https://doi.org/10.1002/aic.690160403, 1970.

Lombardo, C. P., \& Gregg, M. C.: Similarity scaling of viscous and thermal dissipation in a convecting surface boundary layer. J. Geophys. Res., 94, 6273-6284, https://doi.org/10.1029/jc094ic05p06273, 1989.

555 Lorke, A. and Peeters, F.: Toward a unified scaling relation for interfacial fluxes, J. Phys. Oceanogr., 36, 955-961, https://doi.org/10.1175/JPO2903.1, 2006.

Maberly, S. C., Barker, P. A., Stott, A. W. and De Ville, M. M.: Catchment productivity controls $\mathrm{CO}_{2}$ emissions from lakes, 
Nat. Clim. Change, 3, 391-394, https://doi.org/10.1038/nclimate1748, 2013.

MacIntyre, S., Jonsson, A., Jansson, M., Aberg, J., Turney, D. E. and Miller, S. D.: Buoyancy flux, turbulence, and the gas transfer coefficient in a stratified lake: Turbulence and gas evasion in lakes, Geophys. Res. Lett., 37, L24604, https://doi.org/10.1029/2010GL044164, 2010.

MacIntyre, S., Eugster, W. and Kling, G. W.: The critical importance of buoyancy flux for gas flux across the air-water interface, in Geophysical Monograph Series, edited by M. A. Donelan, W. M. Drennan, E. S. Saltzman, and R. Wanninkhof, pp. 135-139, American Geophysical Union, Washington, D. C., https://doi.org/10.1029/GM127p0135, 2001.

Mammarella, I., Nordbo, A., Rannik, Ü., Haapanala, S., Levula, J., Laakso, H., Ojala, A., Peltola, O., Heiskanen, J., Pumpanen, J. and Vesala, T.: Carbon dioxide and energy fluxes over a small boreal lake in Southern Finland: $\mathrm{CO}_{2}$ and Energy Fluxes Over Lake, J. Geophys. Res. Biogeosci., 120, 1296-1314, https://doi.org/10.1002/2014JG002873, 2015.

Perga, M.-E., Maberly, S. C., Jenny, J.-P., Alric, B., Pignol, C. and Naffrechoux, E.: A century of human-driven changes in the carbon dioxide concentration of lakes: 150 years of human impacts on lakes $\mathrm{CO}_{2}$, Global Biogeochem. Cy., 30, 93-104, https://doi.org/10.1002/2015GB005286, 2016.

Raymond, P. A., Hartmann, J., Lauerwald, R., Sobek, S., McDonald, C., Hoover, M., Butman, D., Striegl, R., Mayorga, E., Humborg, C., Kortelainen, P., Dürr, H., Meybeck, M., Ciais, P. and Guth, P.: Global carbon dioxide emissions from inland waters, Nature, 503, 355-359, https://doi.org/10.1038/nature12760, 2013.

Read, J. S., Hamilton, D. P., Desai, A. R., Rose, K. C., MacIntyre, S., Lenters, J. D., Smyth, R. L., Hanson, P. C., Cole, J. J.,

Staehr, P. A., Rusak, J. A., Pierson, D. C., Brookes, J. D., Laas, A. and Wu, C. H.: Lake-size dependency of wind shear and convection as controls on gas exchange: Lake-size dependency of $\boldsymbol{u}_{*}$ and $w_{*}$, Geophys. Res. Lett., 39, L09405, https://doi.org/10.1029/2012GL051886, 2012.

Reed, D. E., Dugan, H. A., Flannery, A. L. and Desai, A. R.: Carbon sink and source dynamics of a eutrophic deep lake using multiple flux observations over multiple years: Carbon sink and source dynamics, Limnol. Oceanogr. Lett., 3, 285-292, 580 https://doi.org/10.1002/lol2.10075, 2018.

Reichl, B. G. and Deike, L.: Contribution of sea-state dependent bubbles to air-sea carbon dioxide fluxes, Geophys. Res. Lett., 47, L087267, https://doi.org/10.1029/2020GL087267, 2020.

Rimet, F., Anneville, O., Barbet, D., Chardon, C., Crépin, L., Domaizon, I., Monet, G.: The Observatory on LAkes (OLA) database: Sixty years of environmental data accessible to the public. J. Limnol., 78, 164-178. doi:114810.4081/jlimnol.2020.1944, 2020.

Risk, D., Nickerson, N., Creelman, C., McArthur, G. and Owens, J.: Forced Diffusion soil flux: A new technique for continuous monitoring of soil gas efflux, Agr. Forest Meteorol., 151, 1622-1631, https://doi.org/10.1016/j.agrformet.2011.06.020, 2011. Russell, T. W. F. and Denn, M. M.: Introduction to chemical engineering analysis, Wiley., 1972.

Schilder, J., Bastviken, D., van Hardenbroek, M., Kankaala, P., Rinta, P., Stötter, T. and Heiri, O.: Spatial heterogeneity and lake morphology affect diffusive greenhouse gas emission estimates of lakes: Spatial heterogeneity of diffusive flux, Geophys. Res. Lett., 40, 5752-5756, https://doi.org/10.1002/2013GL057669, 2013. 
Schubert, M., Paschke, A., Lieberman, E. and Burnett, W. C.: Air-Water Partitioning of ${ }^{222} \mathrm{Rn}$ and its Dependence on Water Temperature and Salinity, Environ. Sci. Technol., 46, 3905-3911, https://doi.org/10.1021/es204680n, 2012.

Simon, A.: Turbulent mixing in the surface boundary layer of lakes, Doctoral dissertation submitted to the Swiss Federal Institute of Technology Zurich, 1997.

Soloviev, A., Donelan, M., Graber, H., Haus, B. and Schlüssel, P.: An approach to estimation of near-surface turbulence and $\mathrm{CO}_{2}$ transfer velocity from remote sensing data, Journal of Marine Systems, 66, 182-194, https://doi.org/10.1016/j.jmarsys.2006.03.023, 2007.

Soloviev, A., Lukas, R., 2006. The Near-Surface Layer of the Ocean: Structure, Dynamics, and Applications, Springer, 572 pp., https//doi.org/10.1007/978-94-007-7621-0, 2006.

Soloviev, A. and Schlüssel P.: Parametrization of the cool skin of the ocean and of the air-ocean gas transfer on the basis of modeling surface renewal, J. Phys. Oceanogr., 24, 1339-1346, 1994.

Stumm, W. and Morgan, J. J.: Aquatic Chemistry: An introduction emphasizing chemical equilibria in natural waters, 2nd Edition., 1981.

605 Tedford, E. W., MacIntyre, S., Miller, S. D. and Czikowsky, M. J.: Similarity scaling of turbulence in a temperate lake during fall cooling, J. Geophys. Res.-Oceans, 119, 4689-4713, https://doi.org/10.1002/2014JC010135, 2014.

Terray, E. A., Donelan, M. A., Agrawal, Y. C., Drennan, W. M., Kahma, K. K., Williams III, A. J., Hwang, P. A. and Kitaigorodkii, S. A.: Estimates of kinetic energy dissipation under breaking waves, J. Phys. Oceanogr., 26, 792-807, 1996.

Toba, Y.: Stochastic form of the growth of wind waves in a single-parameter representation with physical implications, J. of

Physical Oceanography, 8, 494-507, https://doi.org/10.1175/1520-0485(1978)008<0494:SFOTGO>2.0.CO;2, 1978.

Toba, Y.: Local balance in the air-sea boundary processes, J. Oceanogr., 28, 109-120, https://doi.org/10.1007/BF02109772, 1972.

Tranvik, L. J., Downing, J. A., Cotner, J. B., Loiselle, S. A., Striegl, R. G., Ballatore, T. J., Dillon, P., Finlay, K., Fortino, K., Knoll, L. B., Kortelainen, P. L., Kutser, T., Larsen, Soren., Laurion, I., Leech, D. M., McCallister, S. L., McKnight, D. M.,

615 Melack, J. M., Overholt, E., Porter, J. A., Prairie, Y., Renwick, W. H., Roland, F., Sherman, B. S., Schindler, D. W., Sobek, S., Tremblay, A., Vanni, M. J., Verschoor, A. M., von Wachenfeldt, E. and Weyhenmeyer, G. A.: Lakes and reservoirs as regulators of carbon cycling and climate, Limnol. Oceanogr., 54, 2298-2314, https://doi.org/10.4319/lo.2009.54.6_part_2.2298, 2009.

Vachon, D. and Prairie, Y. T.: The ecosystem size and shape dependence of gas transfer velocity versus wind speed relationships in lakes, Can. J. Fish. Aquat. Sci., 70, 1757-1764, https://doi.org/10.1139/cjfas-2013-0241, 2013.

Vachon, D., Prairie, Y. T. and Cole, J. J.: The relationship between near-surface turbulence and gas transfer velocity in freshwater systems and its implications for floating chamber measurements of gas exchange, Limnol. Oceanogr., 55, 17231732, https://doi.org/10.4319/lo.2010.55.4.1723, 2010.

Vesala, T., Huotari, J., Rannik, Ü., Suni, T., Smolander, S., Sogachev, A., Launiainen, S. and Ojala, A.: Eddy covariance 
Geophys. Res., 111, D11101, https://doi.org/10.1029/2005JD006365, 2006.

Wanninkhof, R.: Relationship between wind speed and gas exchange over the ocean, J. Geophys. Res., 97, 7373-7382, https://doi.org/10.1029/92JC00188, 1992.

Winslow, L. A., Zwart, J. A., Batt, R. D., Dugan, H. A., Woolway, R. I., Corman, J. R., Hanson, P. C., \& Read, J. S.:

LakeMetabolizer: An R package for estimating lake metabolism from free-water oxygen using diverse statistical models, Inland Waters, 6, 622-636. https://doi.org/10.1080/IW-6.4.883, 2016.

Wyngaard, J. C. and Coté O.R.: The budgets of turbulent kinetic energy and temperature variance in the atmospheric surface layer, J. Atmos. Sci., 28, 190-201, 1971.

Woolf, D. K.: Parametrization of gas transfer velocities and sea-state-dependent wave breaking, Tellus B, 57, 87-94, https://doi.org/10.3402/tellusb.v57i2.16783, 2005.

Woolf, D. K.: Bubbles and their role in gas exchange, in The Sea Surface and Global Change, edited by P. S. Liss and R. A. Duce, pp. 173-206, Cambridge University Press, https://doi.org/10.1017/CBO9780511525025.007, 1997.

Wüest, A. and Lorke, A.: Small-scale hydrodynamics in lakes, Annu. Rev. Fluid Mech., 35, 373-412, https://doi.org/10.1146/annurev.fluid.35.101101.161220, 2003.

640 Zappa, C. J., McGillis, W. R., Raymond, P. A., Edson, J. B., Hintsa, E. J., Zemmelink, H. J., Dacey, J. W. H. and Ho, D. T.: Environmental turbulent mixing controls on air-water gas exchange in marine and aquatic systems, Geophys. Res. Lett., 34, L10601, https://doi.org/10.1029/2006GL028790, 2007.

Zimmermann, M., Mayr, M. J., Bouffard, D., Eugster, W., Steinsberger, T., Wehrli, B., Brand, A., Bürgmann, H.: Lake overturn as a key driver for methan oxidation, CSH. Lab. bioRXiv, https://doi.org/10.1101/689182, 2019. 


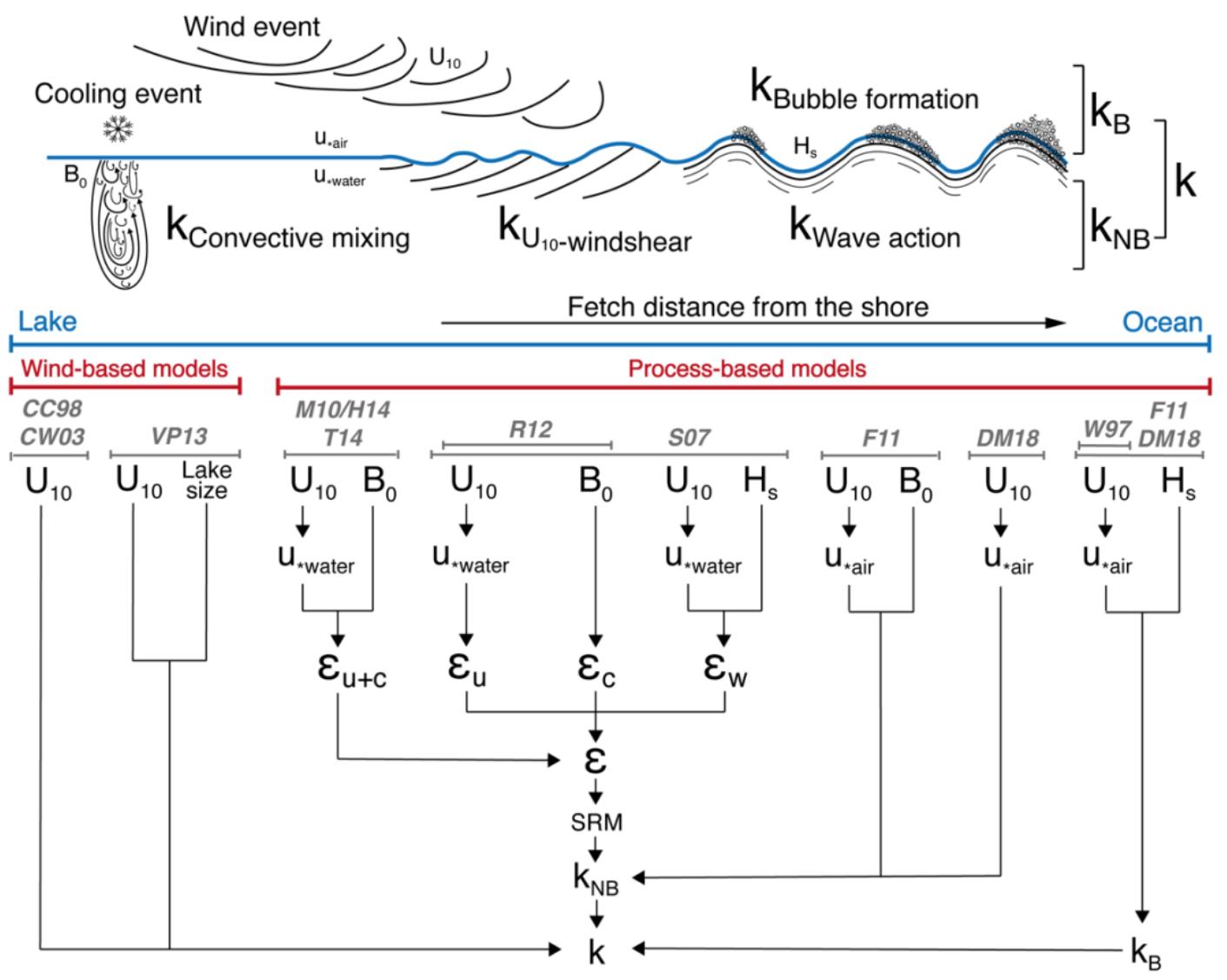

Figure 1: Conceptual scheme of the four main processes driving gas transfer velocity $(k)$ in a large lake induced by wind and cooling events. These four processes are split into two types of $k: k$-bubble for the bubble formation $\left(k_{\mathrm{B}}=k_{\mathrm{b}}\right)$ and $k$-no bubble for the convective mixing, wind shear and wave action term which are added $\left(k_{\mathrm{NB}}=k_{\mathrm{c}}+k_{\mathrm{u}}+k_{\mathrm{w}}\right)$. Below this scheme, a non-exhaustive review about conceptual approaches of $k$-models used in $1^{\text {st }}$ Fickian law. From left to right, increase in the complexity level of $k$-models as well as their study site (limnological to oceanic case). All these variables are described in the section 2.4 and in Table 1. 


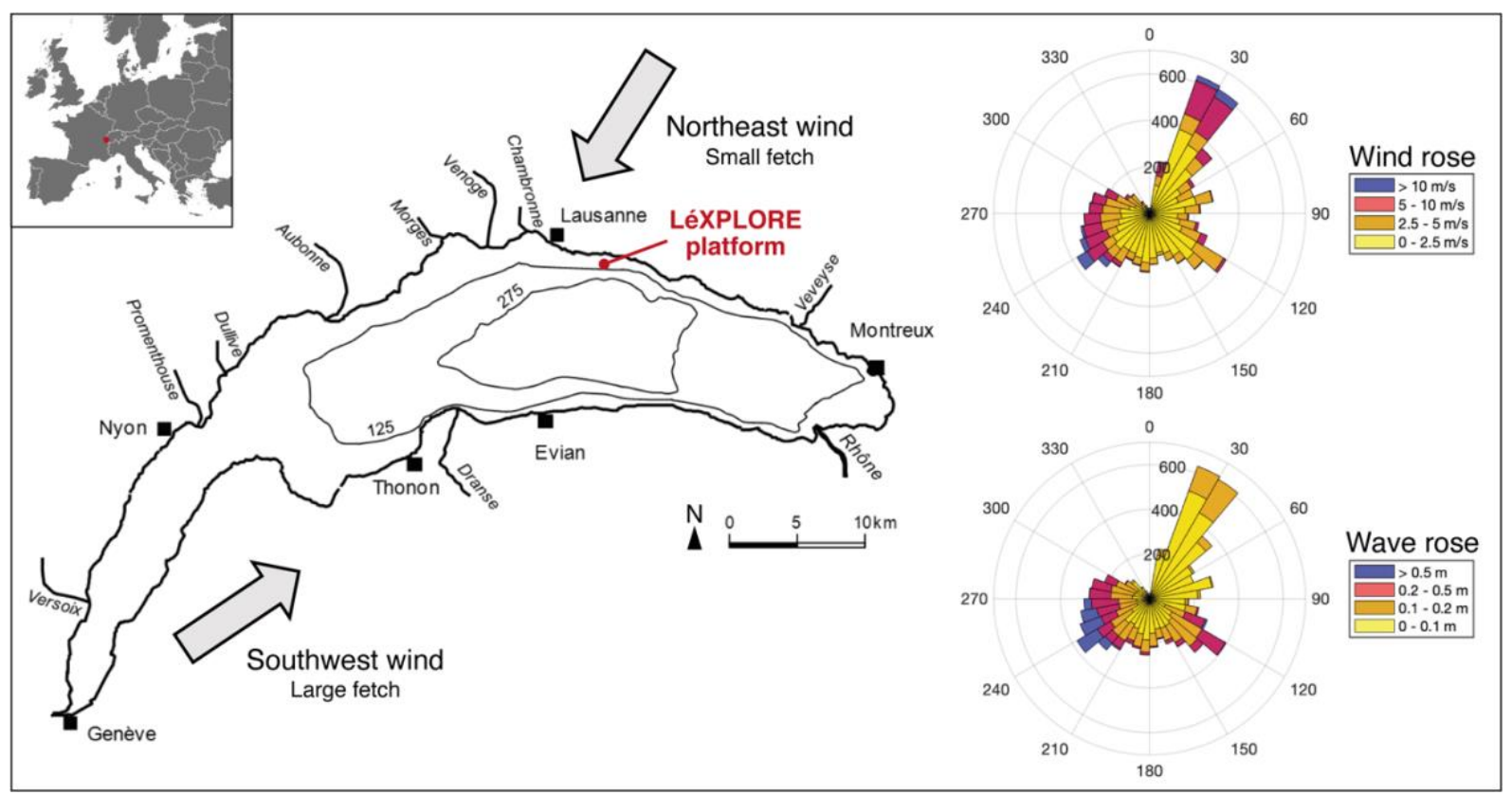

Figure 2: Location and map of Lake Geneva with the two prevailing winds (left side) also depicted by the wind rose (top right side). The wave rose highlights the highest wavefield generated at the sampling location by the southwest wind with a larger fetch (bottom right side). Both wind and wave roses are computed with annual data from $13^{\text {th }} \mathrm{June}^{\text {. }}$ 2019 to $12^{\text {th }}$ June 2020 at LéXPLORE.
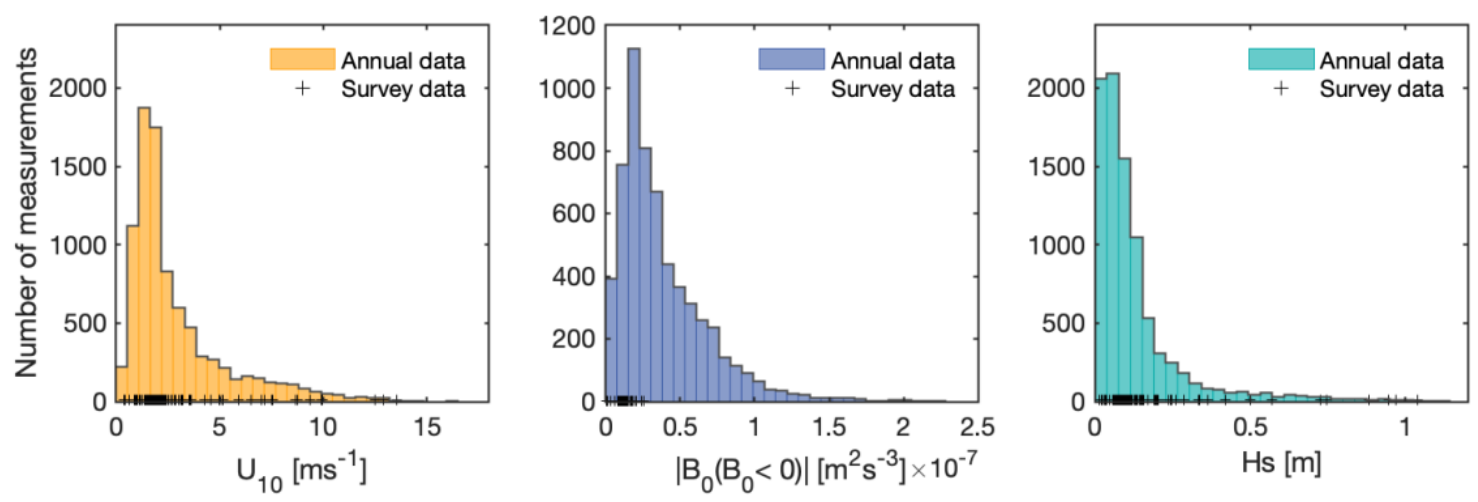

Figure 3: Annual distribution of three main components used to compute $k_{600}$ models. Orange) Wind speed at $10 \mathrm{~m}$; Blue) Buoyancy flux at surface during cooling; Turquoise) Significant wave height; and these survey data observed during $\mathrm{CO}_{2}$ flux measurements after quality control (+). 

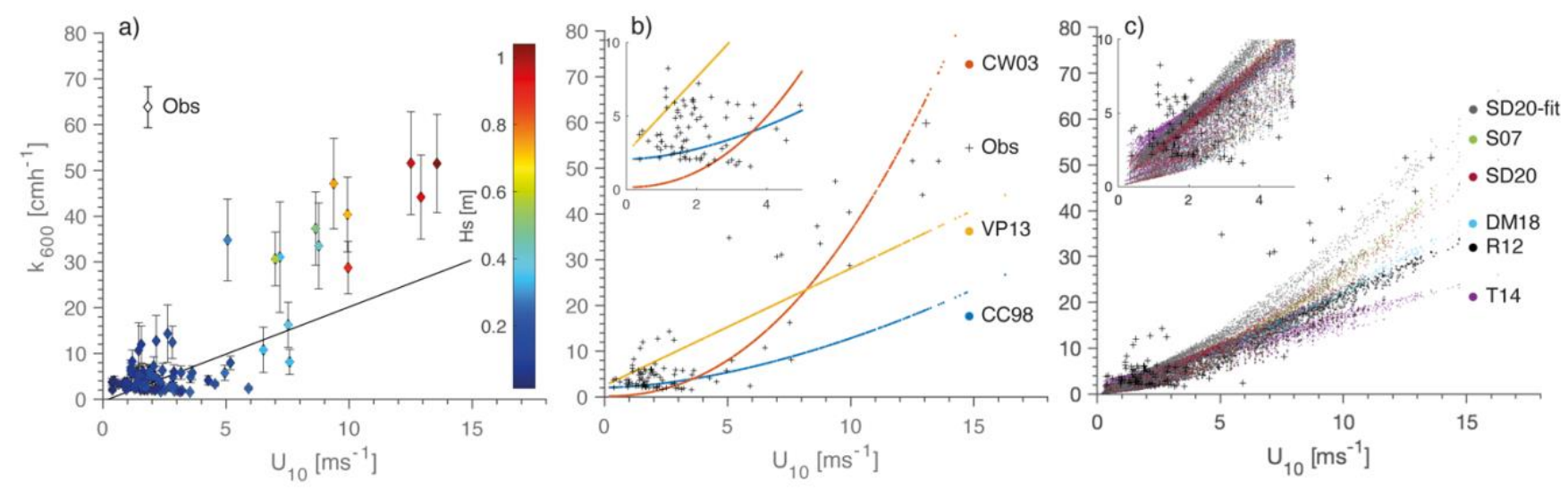

665 Figure 4: a) $k_{600}$ observed as a function of $U_{10}$ and coloured according to $H_{s}$ (colorbar), and the error bars produced by the uncertainty of $\triangle \mathrm{CO}_{2}( \pm 50 \mathrm{ppm})$ as well as the $u_{*}-k_{600}$ linear regression (solid line: see also Fig. B1); b) $k_{600}$ windbased models $(C C 98, C W 03 \& \mathrm{VP13})$; c) $k_{600}$ process-based models $(T 14, S 07, D M 18, S D 20 \& S D 20-f i t)$ computed with annual data; Observed $k_{600}$ derived from $\mathrm{CO}_{2}$ flux chamber measurements (+).
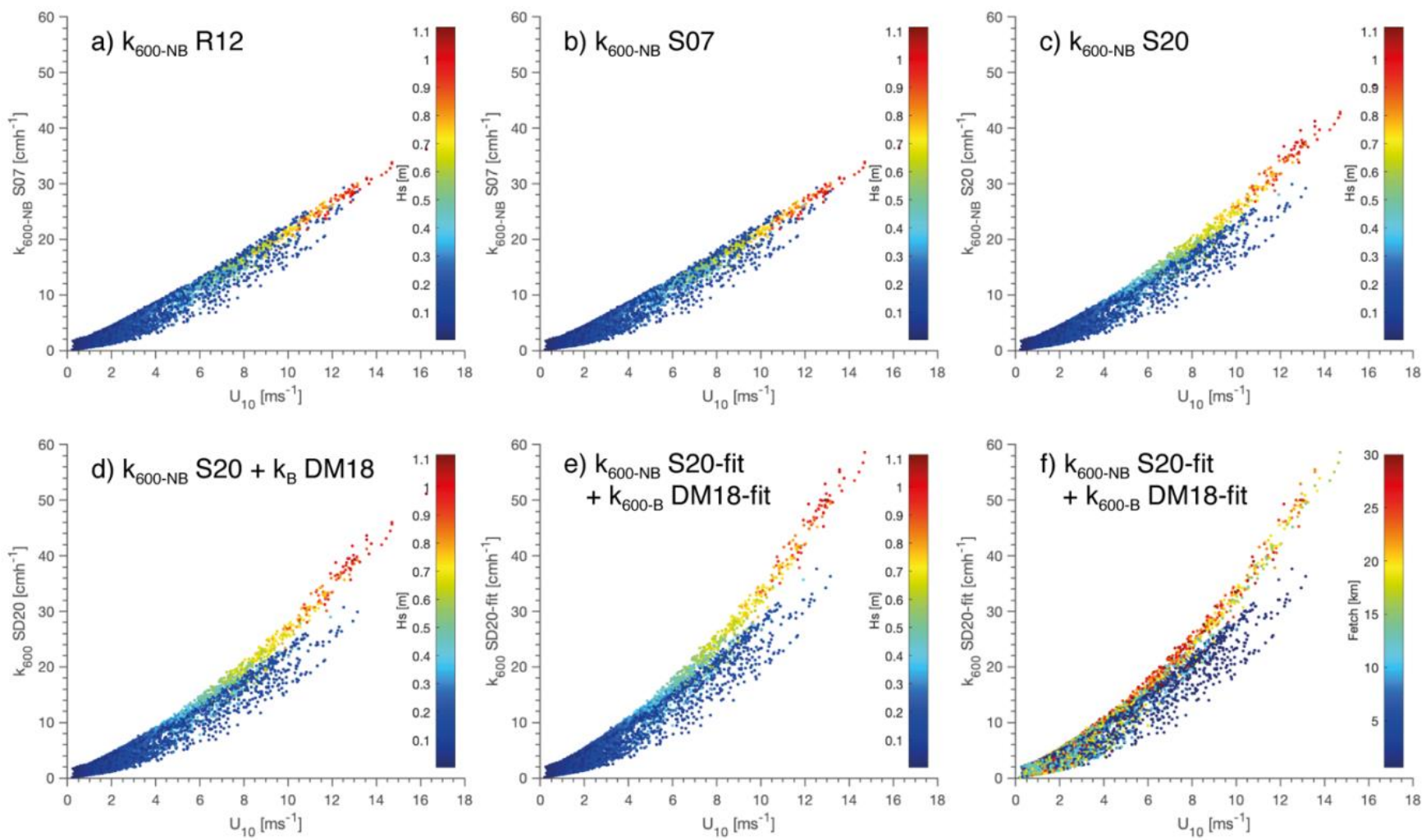

670 Figure 5: Relation $U_{10}$ vs $\boldsymbol{k}_{600}$ modelled and coloured according to $\boldsymbol{H}_{\mathrm{s}}$ (colorbar) in a-b-c-d-e as well as coloured according to fetch distance (colorbar) in $\mathrm{f}$. a) $R 12$ integrating wind shear and convection; b) S07 integrating wind shear, convection, and wave action for fully developed waves; c) $S 20$ integrating wind shear, convection, and wave action for not fully developed waves; d) $S D 20$ similar to $S 20$ adding the $k$ bubble term of $D M 18$; e-f) $S D 20$-fit similar to $S D 20$ with $a_{1}$ and $A_{\mathrm{b}}$ fitted to $k$ observed. 

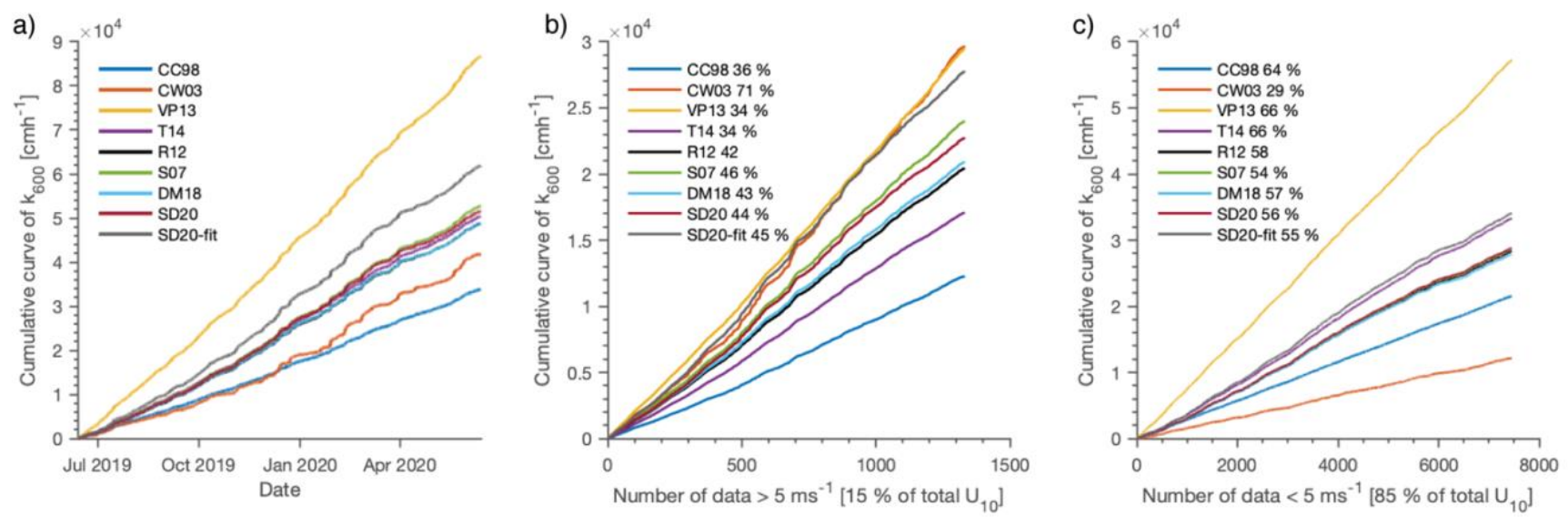

Figure 6: a) Cumulative $k_{600}$ modelled over an annual cycle; b) Cumulative $k_{600}$ for wind $<5 \mathrm{~m} \mathrm{~s}^{-1}$; c) Cumulative $k_{600}$ for wind $\geq 5 \mathrm{~m} \mathrm{~s}^{-1}$.
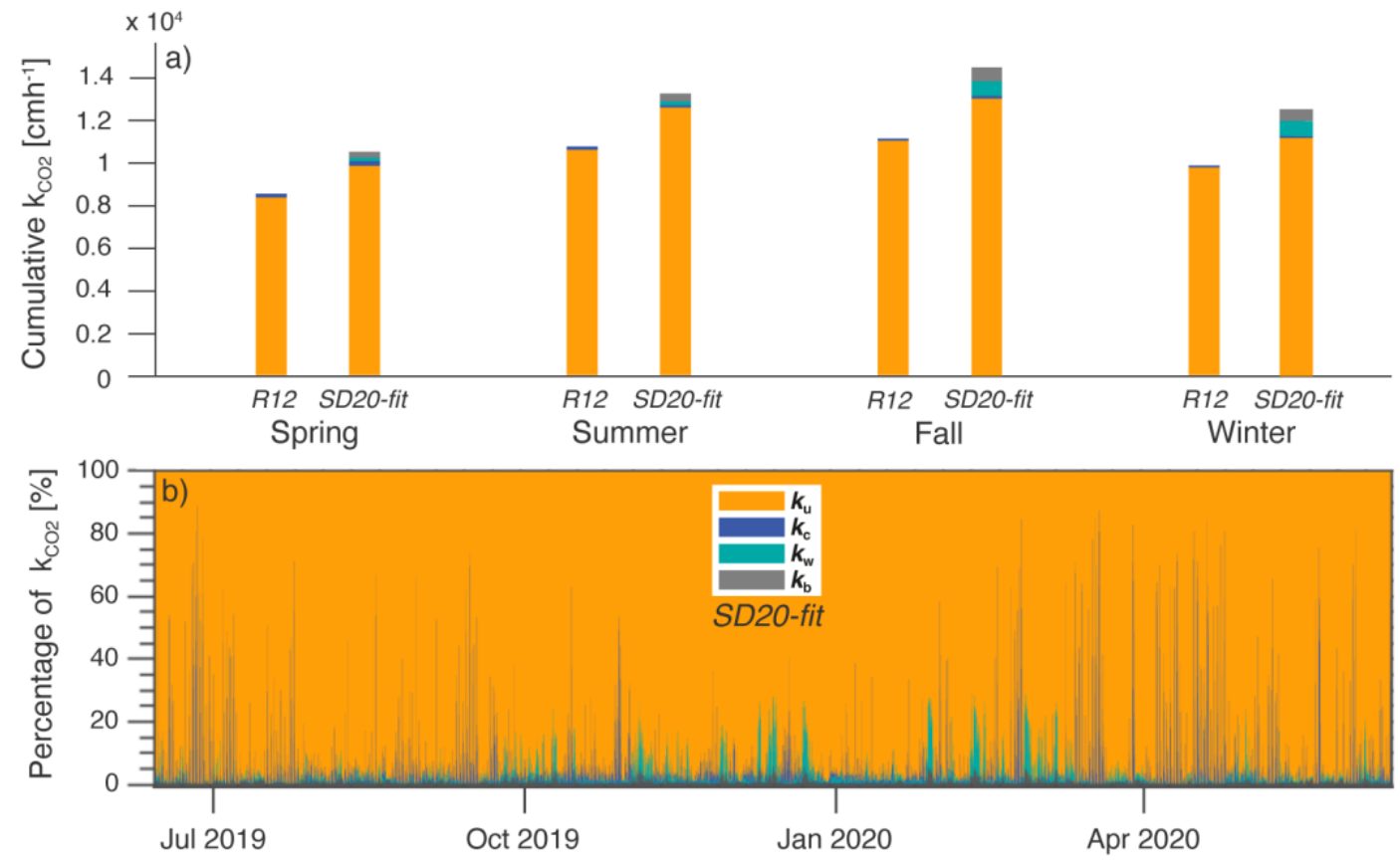

Hours from June $13^{\text {th }} 2019$ to June $12^{\text {th }} 2020$

680 Figure 7: a) Distribution of $k_{\mathrm{CO} 2}$ generated by two main processes ( $k_{\mathrm{u}}$ and $\left.k_{\mathrm{c}}\right)$ in $R 12$ and four main processes $\left(k_{\mathrm{u}}, \boldsymbol{k}_{\mathrm{c}}, \boldsymbol{k}_{\mathrm{w}}\right.$, and $k_{\mathrm{b}}$ ) in SD20-fit for each season; Spring (April-May-June); Summer (July-August-September); Fall (OctoberNovember-December); Winter (January-February-March). The height of bar represents the cumulative of $k_{\mathrm{CO} 2}$ by season for both models (R12 and $S D 20-f i t)$; b) Distribution of four $k$ generated by wind shear, convection, wave action and bubble enhancement $\left(k_{u}, k_{c}, k_{w}\right.$, and $\left.k_{b}\right)$ along the annual cycle. Use of SD20-fit model where $\boldsymbol{k}_{u}=S R M\left(\varepsilon_{u}\right), \boldsymbol{k}_{c}=$ $\operatorname{SRM}\left(\varepsilon_{u}+\varepsilon_{c}+\varepsilon_{w}\right)-\operatorname{SRM}\left(\varepsilon_{u}+\varepsilon_{w}\right), k_{w}=\operatorname{SRM}\left(\varepsilon_{u}+\varepsilon_{c}+\varepsilon_{w}\right)-\operatorname{SRM}\left(\varepsilon_{u}+\varepsilon_{c}\right)$, and $k_{b}$. 
Table 1: Summary of characteristics of $\boldsymbol{k}_{S c}$ models for predicting the air-water gas transfer velocity based on wind speed (CC98, CW03) and lake size (VP13), surface renewal model (T14, R12 \& S07), COARSE approach (DM18) and both adapted models called SD20 and SD20-fit from a combination of $S 07$ and $D M 18$.

\begin{tabular}{|c|c|c|c|c|}
\hline Model & Equation & Method & Site & Calibrated range \\
\hline CC98 & $\begin{array}{c}k_{600}=2.07+0.215 \cdot U_{10}^{1.7} \\
k_{S c}=k_{600}\left(\frac{S c}{600}\right)^{-1 / 2}\end{array}$ & $\begin{array}{l}\text { Mass Balance } \\
\text { By gas tracer }\end{array}$ & Lake & $\begin{array}{l}\text { Area }\left(0.15 \mathrm{~km}^{2}\right) \\
U_{10}\left(<9 \mathrm{~ms}^{-1}\right)\end{array}$ \\
\hline CW03 & $\begin{array}{c}k_{600}=0.168+0.228 \cdot U_{10}^{2.2} \\
k_{S c}=k_{600}\left(\frac{S c}{600}\right)^{-1 / 2}\end{array}$ & $\begin{array}{l}\text { Mass Balance } \\
\text { By gas tracer }\end{array}$ & Lake & $\begin{array}{l}\text { Area }\left(0.128 \mathrm{~km}^{2}\right) \\
U_{10}\left(<6 \mathrm{~ms}^{-1}\right)\end{array}$ \\
\hline$V P 13$ & $\begin{array}{c}k_{600}=2.51+\left(1.48 \cdot U_{10}\right)+\left(0.39 \cdot U_{10}\right. \\
\cdot \log 10(\text { Lake size }) \\
k_{S c}=k_{600}\left(\frac{S c}{600}\right)^{-1 / 2}\end{array}$ & $\begin{array}{l}\text { Floating } \\
\text { Chamber }\end{array}$ & Lakes & $\begin{array}{l}\text { Area }\left(0.2-602 \mathrm{~km}^{2}\right) \\
U_{10}\left(<6 \mathrm{~ms}^{-1}\right)\end{array}$ \\
\hline$T 14$ & $\begin{array}{l}k_{S c}=a_{1} \cdot(\varepsilon \cdot v)^{1 / 4} \cdot S c^{-1 / 2} \\
\varepsilon=\varepsilon_{\text {Wind }} \text { shear }+ \text { Convection }\end{array}$ & $\begin{array}{l}\text { Microstructure } \\
\text { profiling }\end{array}$ & Lake & $\begin{array}{l}\text { Area }\left(4 \mathrm{~km}^{2}\right) \\
U_{10}\left(<10 \mathrm{~ms}^{-1}\right)\end{array}$ \\
\hline$R 12$ & $\begin{array}{l}k_{S c}=a_{1} \cdot(\varepsilon \cdot v)^{1 / 4} \cdot S c^{-1 / 2} \\
\varepsilon=\varepsilon_{\text {Wind shear }}+\varepsilon_{\text {Convection }}\end{array}$ & - & - & Following SO7 \\
\hline SO7 & $\begin{array}{r}k_{S C}=k_{S C-N B-S 07}+k_{S C-B-W 97} \\
k_{S c-N B}=a_{1} \cdot(\varepsilon \cdot v)^{1 / 4} \cdot S c^{-1 / 2} \\
\varepsilon=\varepsilon_{\text {Wind shear }}+\varepsilon_{\text {Convection }} \\
+\varepsilon_{\text {Wave action }}\end{array}$ & $\begin{array}{l}\text { Eddy } \\
\text { covariance }\end{array}$ & Ocean & $\begin{array}{l}\text { Area }\left(>100^{\prime} 000 \mathrm{~km}^{2}\right) \\
U_{10}\left(<20 \mathrm{~ms}^{-1}\right) \\
\text { Wave }(0-10 \mathrm{~m})\end{array}$ \\
\hline DM18 & $\begin{array}{c}k_{S c}=\left(k_{N B}+k_{B}\right) \cdot(S c / 600)^{-1 / 2} \\
k_{N B}=A_{N B} \cdot u_{*, a t m} \\
k_{B}=\left(A_{B} / O_{S}\right) \cdot u_{*, a t m}^{5 / 3} \cdot\left(g \cdot H_{S}\right)^{2 / 3}\end{array}$ & $\begin{array}{l}\text { Eddy } \\
\text { Covariance }\end{array}$ & Ocean & $\begin{array}{l}\text { Area }\left(>100^{\prime} 000 \mathrm{~km}^{2}\right) \\
U_{10}\left(<30 \mathrm{~ms}^{-1}\right) \\
\text { Wave }(1-10 \mathrm{~m})\end{array}$ \\
\hline$S D 20$ & $\begin{array}{c}k_{S C}=k_{S C-N B-S 07 *}+k_{S c-B-D M 18} \\
* \text { Adaptation of } \varepsilon_{\text {Wave action }} \text { for large lake }\end{array}$ & $\begin{array}{l}\text { Floating } \\
\text { Chamber }\end{array}$ & Lake & $\begin{array}{l}\text { Area }\left(582 \mathrm{~km}^{2}\right) \\
U_{10}\left(<16 \mathrm{~ms}^{-1}\right) \\
\text { Wave }(0-1.2 \mathrm{~m})\end{array}$ \\
\hline SD20-fit & $\begin{array}{c}k_{S C}=k_{S C-N B-S 07 *}+k_{S C-B-D M 18} \\
\text { with } a_{1} \text { from } k_{S C-N B-S 07 *} \text { and } A_{B} \text { from } \\
k_{S C-B-D M 18} \text { fitted to observations }\end{array}$ & - & - & - \\
\hline
\end{tabular}

CC98 Cole and Caraco (1998), CW03 Crusius and Wanninkhof (2003), VP13 Vachon and Prairie (2013), T14 Tedford et al. (2014), R12 Read et al. (2012), S07 Soloviev et al. (2007), DM18 Deike and Melville (2018). 
Table 2: RMSE of $k_{600}$ models for all wind speed $\left(U_{10}\right), U_{10}<5 \mathrm{~m} \mathrm{~s}^{-1}$ (i.e., $\left.L W\right)$ and $U_{10} \geq 5 \mathrm{~m} \mathrm{~s}^{-1}$ (i.e., SW).

\begin{tabular}{|c|c|c|c|c|c|c|c|c|c|}
\hline RMSE & $C C 98$ & $C W 03$ & VP13 & T14 & R12 & S07 & DM18 & SD20 & SD20-fit \\
\hline All $U_{10}$ & 9.8 & 6.5 & 6.7 & 8.6 & 7.5 & 6.2 & 7.3 & 6.2 & 5.2 \\
\hline$U_{10}<5 \mathrm{~ms}^{-1}$ & 3.2 & 4.2 & 4.5 & 2.9 & 3.3 & 3.3 & 3.5 & 3.3 & 3.2 \\
\hline$U_{10} \geq 5 \mathrm{~ms}^{-1}$ & 22.8 & 12.8 & 12.7 & 19.8 & 16.6 & 13 & 15.9 & 13.1 & 10.5 \\
\hline
\end{tabular}

Table 3: Monthly to annual $\mathrm{CO}_{2}$ flux estimation $\left(\mathrm{mmolC} \mathrm{m}^{-2} \mathrm{~d}^{-1}\right)$ from $k$-models and monthly $\Delta \mathrm{CO}_{2}$ average ( $\mu$ atm) as well as their deviation from SD20-fit.

\begin{tabular}{|c|c|c|c|c|c|c|c|c|c|c|}
\hline Period & $\Delta \mathrm{CO}_{2}$ & СС98 & $C W 03$ & VP13 & $T 14$ & $R 12$ & S07 & DM18 & $S D 20$ & SD20-fit \\
\hline April & 42 & 2.7 & 2.3 & 6.7 & 3.3 & 2.9 & 3.0 & 2.7 & 3.0 & 3.7 \\
\hline May & -110 & -10.0 & -16.1 & -25.2 & -13.2 & -13.3 & -15.2 & -13.2 & -13.5 & -16.8 \\
\hline June & -85 & -5.0 & -4.3 & -12.7 & -6.3 & -5.8 & -6.0 & -5.7 & -6.0 & -7.3 \\
\hline Spring & -51 & -4.2 & -5.9 & -10.5 & -5.5 & -5.4 & -6.2 & -5.5 & -5.6 & -6.9 \\
\hline July & -120 & -8.1 & -8.4 & -21.0 & -11.0 & -10.7 & -11.3 & -10.6 & -11.0 & -13.5 \\
\hline August & -180 & -10.3 & -7.4 & -27.4 & -15.8 & -14.7 & -15.2 & -14.8 & -15.2 & -18.7 \\
\hline September & -140 & -8.7 & -9.0 & -22.7 & -13.3 & -13.1 & -13.7 & -13.0 & -13.3 & -16.7 \\
\hline Summer & -145 & -9.0 & -8.3 & -23.7 & -13.4 & -12.8 & -13.4 & -12.8 & -13.2 & -16.3 \\
\hline October & 10 & 0.6 & 0.6 & 1.6 & 1.0 & 0.9 & 1.0 & 1.0 & 1.0 & 1.3 \\
\hline November & 450 & 35.0 & 42.3 & 93.3 & 59.7 & 59.1 & 62.7 & 59.7 & 63.0 & 78.0 \\
\hline December & 590 & 51.6 & 80.6 & 130.0 & 82.6 & 83.9 & 93.2 & 84.8 & 92.6 & 114.5 \\
\hline Fall & 350 & 29.0 & 41.2 & 74.8 & 47.6 & 47.9 & 52.2 & 48.4 & 52.1 & 64.5 \\
\hline January & 540 & 40.0 & 49.7 & 99.7 & 64.8 & 60.9 & 66.5 & 60.6 & 65.5 & 81.0 \\
\hline February & 500 & 49.3 & 84.8 & 123.4 & 71.4 & 72.5 & 82.1 & 72.8 & 81.0 & 100.0 \\
\hline March & 385 & 40.3 & 56.1 & 102.3 & 61.3 & 60.03 & 65.5 & 59.4 & 63.2 & 78.1 \\
\hline Winter & 475 & 43.1 & 63.1 & 108.1 & 65.7 & 64.5 & 71.1 & 64.1 & 69.7 & 86.0 \\
\hline Annual & 157 & 14.7 & 22.5 & 37.1 & 23.6 & 23.4 & 25.9 & 23.5 & 25.7 & 31.8 \\
\hline $\begin{array}{c}\text { Annual } \\
\mathrm{gCm}^{-2} \mathbf{y r}^{-1}\end{array}$ & - & 64.6 & 98.8 & 163.1 & 103.6 & 102.8 & 113.9 & 103.3 & 113.0 & 139.7 \\
\hline $\begin{array}{c}\text { Deviation } \\
\text { from } S D 20-f i t\end{array}$ & - & $-54 \%$ & $-29 \%$ & $+17 \%$ & $-26 \%$ & $-26 \%$ & $-18 \%$ & $-26 \%$ & $-19 \%$ & - \\
\hline
\end{tabular}




\section{Device operation}

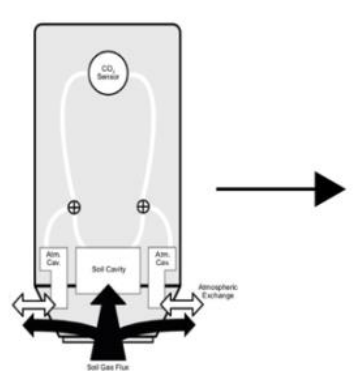

Lab construction

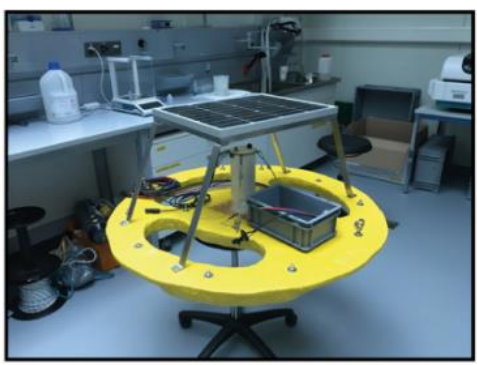

Field measurement

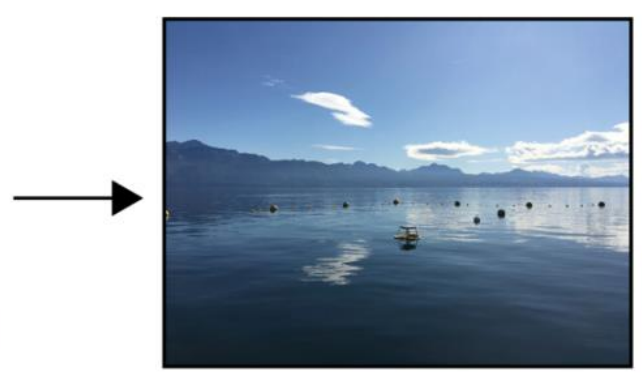

Figure A1: Schematics of eosFD operation (eosense.com) followed by its mini-platform construction and its positioning for measurements in the field (Lake Geneva at LéXPLORE platform). The raft design also complies with recommendations to minimize artificial turbulence induced by the chamber's walls, with $10 \mathrm{~cm}$ long-edges entering the water (Vachon et al., 2010).

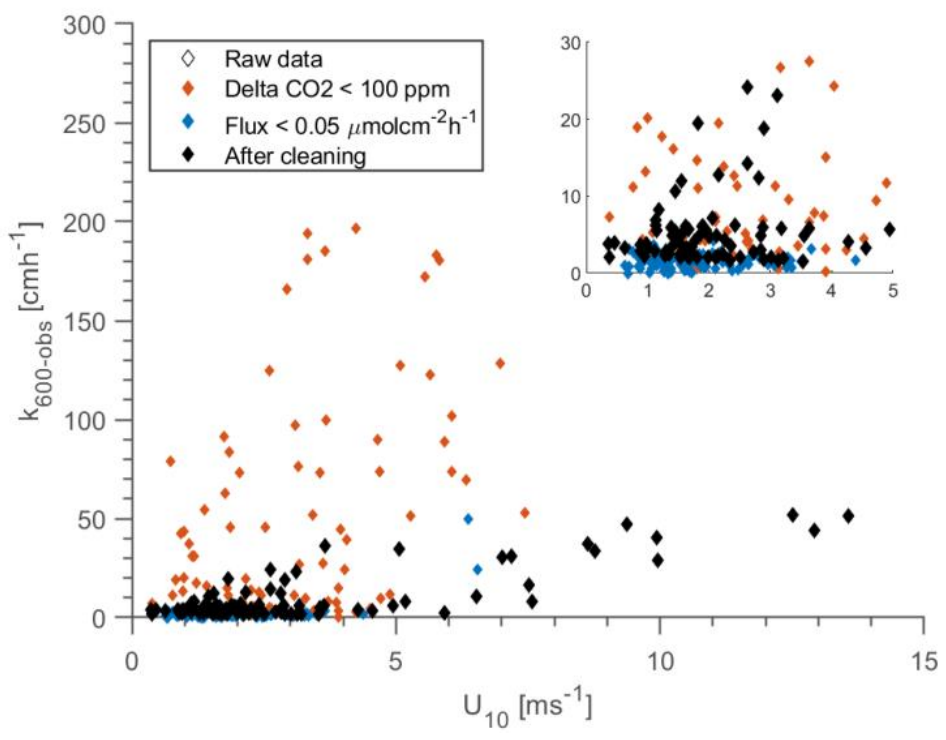

Figure A2: Visualisation of 304 observed $k_{600}$ during the five periods of flux measurements (i.e., $13^{\text {th }}-14^{\text {th }}$ June 2019, $2^{\text {th }}-28^{\text {th }}$ August 2019, $1^{\text {st }}-5^{\text {th }}$ October 2019, 18 $^{\text {th }}-20^{\text {th }}$ December 2019, and $20^{\text {th }}-26^{\text {th }}$ February 2020). 

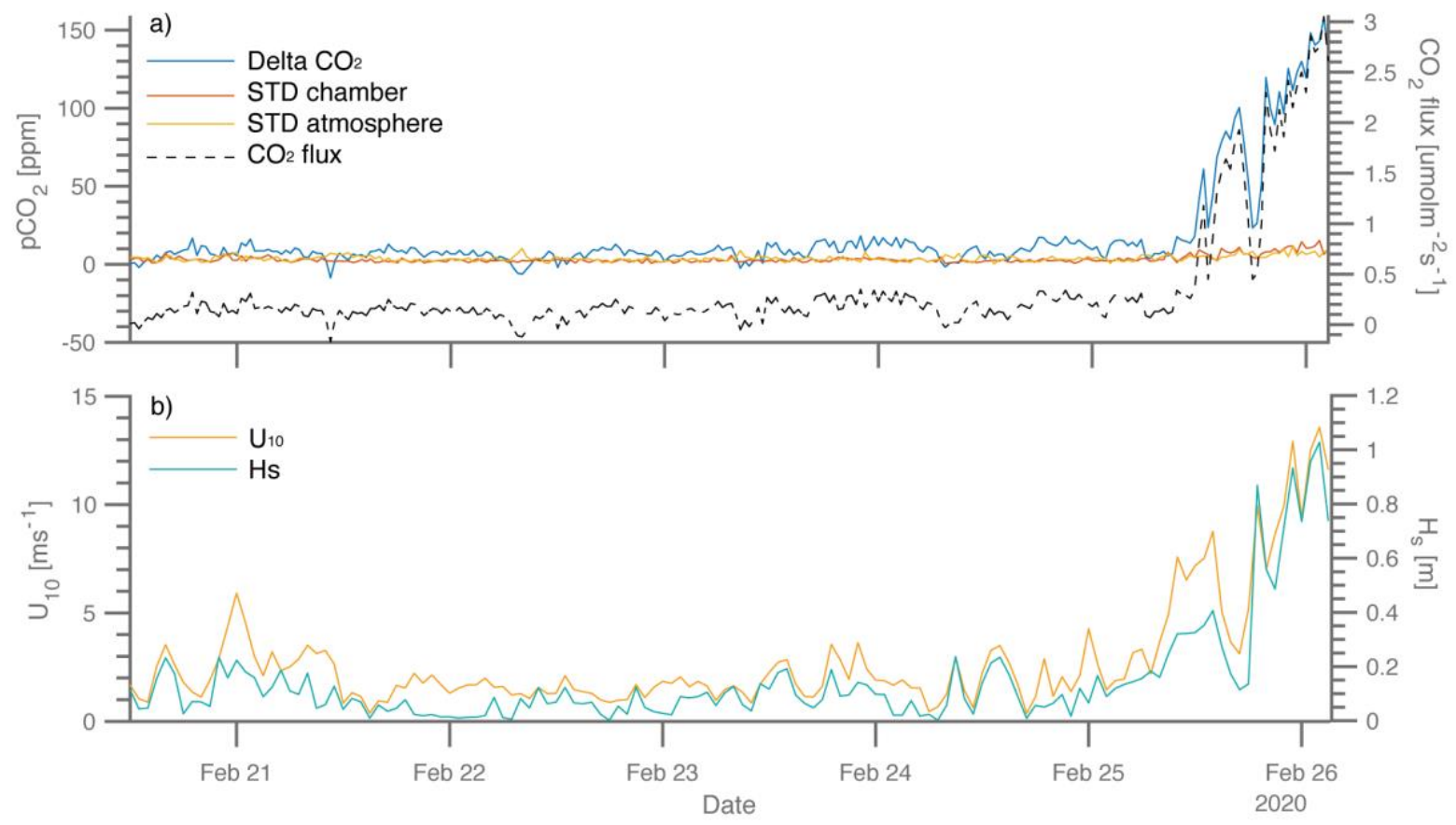

Figure A3: a) Raw outputs of the eosFD during one period of $\mathrm{CO}_{2}$ flux measurements; $\Delta \mathrm{CO}_{2}$ between both cavities of measures (atmosphere cavity and chamber cavity) (blue line); Standard deviation of each cavity between two automated flushing (30 minutes of interval), Chamber cavity (red line), Atmosphere cavity (yellow line); and the $\mathrm{CO}_{2}$ flux (black dash line). b) Temporal evolution of $U_{10}$ and $H_{\mathrm{s}}$ during the same period than $\mathrm{CO}_{2}$ flux measurements. Increase in flux on $25^{\text {th }}$ February corresponding to increase in wind speed and waves.
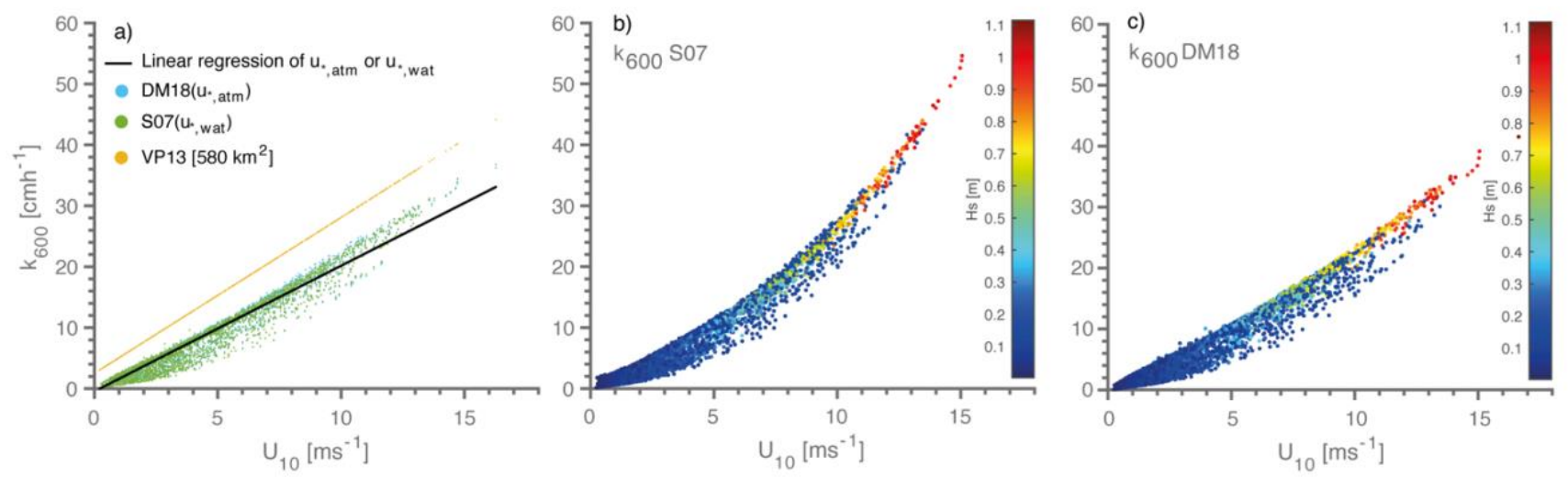

Figure B1: a) Comparison of Soloviev et al. (2007) and Deike and Melville (2018) for the first order function of friction velocity at the water side $\left(\boldsymbol{u}_{*, \text { wat }}\right)$ (blue points) and at the atmosphere side $\left(\boldsymbol{u}_{*, a t m}\right)$ (green points) with their linear regression (black line); the linear function of Vachon and Prairie (2013) for a lake size of $582 \mathbf{~ k m}^{2}$ (yellow points) as well as the linear regression from ; b) Visualisation of $S 07$ with empirical parameterization of bubble term (Woolf, 1997) regardless of wave height in function of wind speed at $10 \mathrm{~m}$; c) Visualisation of $D M 18$ in function of wind speed, only effect of bubble term from $10 \mathrm{~ms}^{-1}$. 
https://doi.org/10.5194/esd-2021-30

Preprint. Discussion started: 7 May 2021

(c) Author(s) 2021. CC BY 4.0 License.
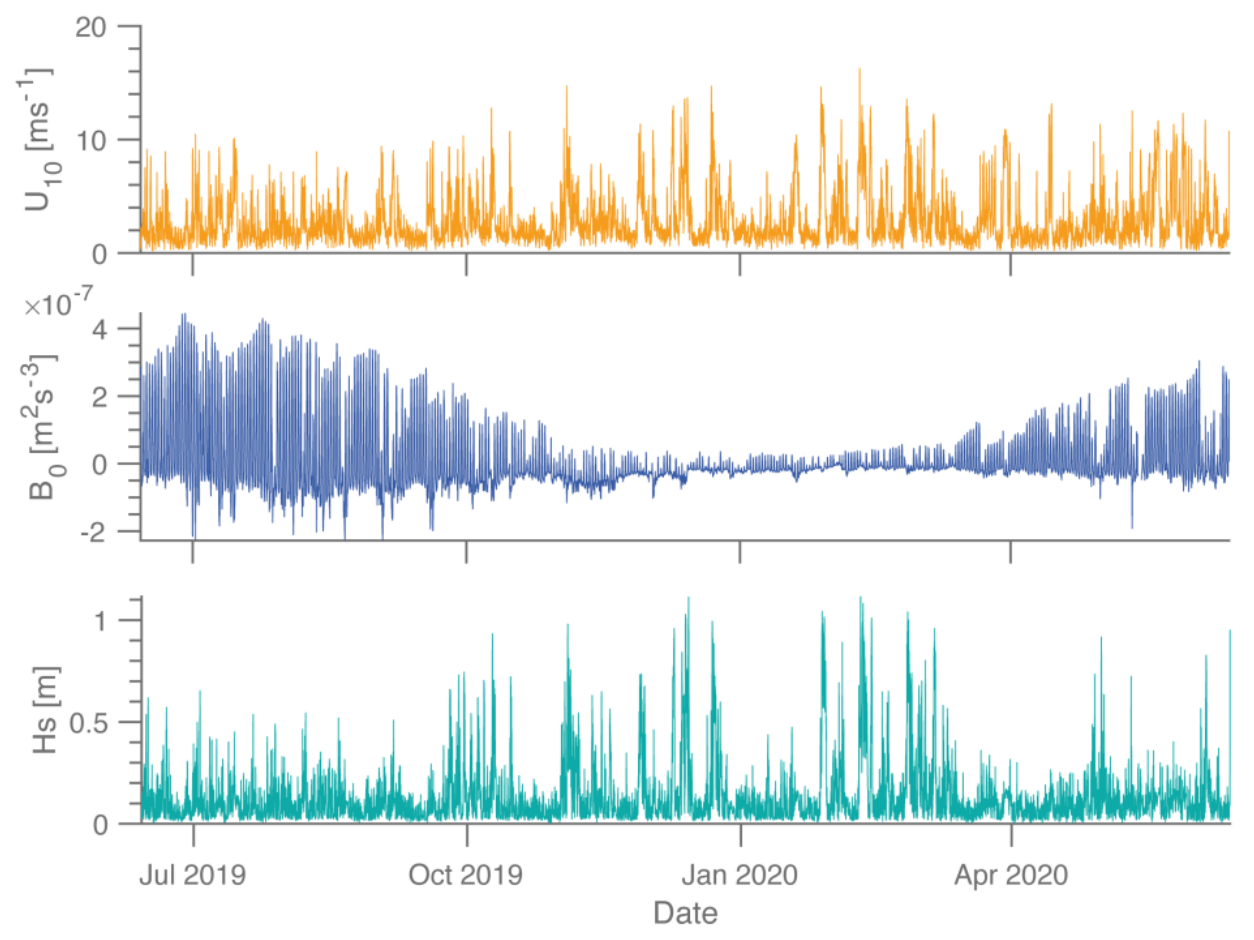

Figure C1: Annual evolution of 3 main inputs of $\boldsymbol{k}$-models; Wind speed at $10 \mathrm{~m}\left(\boldsymbol{U}_{\mathbf{1 0}}\right)$; Buoyancy flux at surface $\left(B_{0}\right)$; 